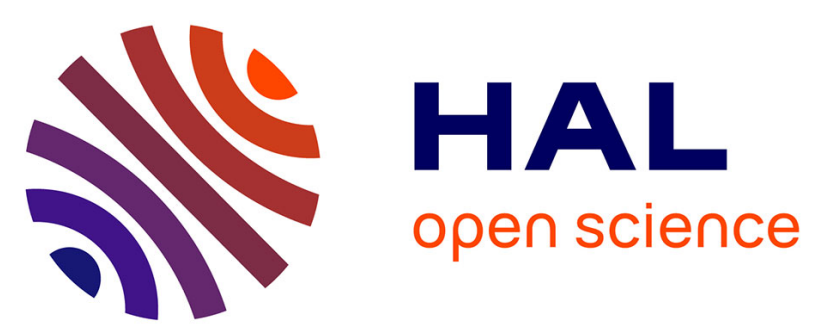

\title{
Thrombolytic Therapy Based On Fucoidan-Functionalized Polymer Nanoparticles Targeting P-selectin
}

Maya Juenet, Rachida Aid-Launais, Bo Li, Alice Berger, Joël Aerts, Antonino Nicoletti, Didier Letourneur, Cédric Chauvierre

\section{To cite this version:}

Maya Juenet, Rachida Aid-Launais, Bo Li, Alice Berger, Joël Aerts, et al.. Thrombolytic Therapy Based On Fucoidan-Functionalized Polymer Nanoparticles Targeting P-selectin. Biomaterials, 2018, pp.204-216. 10.1016/j.biomaterials.2017.11.047 . hal-02438595

\section{HAL Id: hal-02438595 https://hal.science/hal-02438595}

Submitted on 20 Jan 2020

HAL is a multi-disciplinary open access archive for the deposit and dissemination of scientific research documents, whether they are published or not. The documents may come from teaching and research institutions in France or abroad, or from public or private research centers.
L'archive ouverte pluridisciplinaire HAL, est destinée au dépôt et à la diffusion de documents scientifiques de niveau recherche, publiés ou non, émanant des établissements d'enseignement et de recherche français ou étrangers, des laboratoires publics ou privés. 


\title{
Thrombolytic Therapy Based On Fucoidan-Functionalized Polymer Nanoparticles Targeting P-selectin
}

\author{
Maya Juenet $^{1,2}$, Rachida Aid-Launais ${ }^{1,2,3} \dagger$, Bo Li ${ }^{1,2} \dagger$, Alice Berger ${ }^{1,2}$, Joël Aerts ${ }^{3}$, Véronique \\ Ollivier $^{1,2}$, Antonino Nicoletti ${ }^{1,2}$, Didier Letourneur ${ }^{1,2} \dagger$ and Cédric Chauvierre ${ }^{1,2} \dagger^{* *}$ \\ ${ }^{1}$ INSERM, U1148, Laboratory for Vascular Translational Science, X. Bichat Hospital, 46 rue \\ Henri Huchard, 75018, Paris, France \\ ${ }^{2}$ Paris Diderot University, Paris 13 University, Sorbonne Paris Cité, Paris, France \\ ${ }^{3}$ FRIM, INSERM UMS 034 Paris Diderot University, X. Bichat Hospital, 75018, Paris France \\ $\dagger$ Equal contribution \\ *Corresponding author: cedric.chauvierre@inserm.fr $\quad$ Phone: +(33)140257538
}

\section{Abstract:}

Injection of recombinant tissue plasminogen activator (rt-PA) is the standard drug treatment for thrombolysis. However, rt-PA shows risk of hemorrhages and limited efficiency even at high doses. Polysaccharide-poly(isobutylcyanoacrylate) nanoparticles functionalized with fucoidan and loaded with rt-PA were designed to accumulate on the thrombus. Fucoidan has a nanomolar affinity for the P-selectin expressed by activated platelets in the thrombus. Solid spherical fluorescent nanoparticles with a hydrodynamic diameter of $136 \pm 4 \mathrm{~nm}$ were synthesized by redox radical emulsion polymerization. The clinical rt-PA formulation was successfully loaded by adsorption on aminated nanoparticles and able to be released in vitro. We validated the in vitro fibrinolytic activity and binding under flow to both recombinant $\mathrm{P}$-selectin and activated platelet aggregates. The thrombolysis efficiency was demonstrated in a mouse model of venous thrombosis by monitoring the platelet density with intravital microscopy. This study supports the hypothesis that fucoidan-nanoparticles improve the rt-PA efficiency. This work establishes the proof-of-concept of fucoidan-based carriers for targeted thrombolysis.

\section{Keywords:}

Nanomedicine; Thrombolysis; Fucoidan; P-selectin; Drug delivery 


\section{Introduction}

Since the 1990's, intravenous injection of recombinant tissue plasminogen activator (rt-PA) has remained the recommended treatment to induce vessel recanalization in acute thrombotic events such as ischemic stroke $[1,2]$. rt-PA is a serine protease that catalyzes the conversion of plasminogen to plasmin. Plasmin degrades the fibrin network of the thrombus thereby promoting thrombolysis. rt-PA preferentially acts by forming a ternary complex in which both rt-PA and plasminogen are bound to fibrin. However, because of its short half-life, high doses of rt-PA need to be injected which generate a cascade of events in the circulation leading to serious side effects. Intracranial hemorrhages are indeed observed in $6 \%$ of the treated patients causing $50 \%$ of subsequent mortality [3]. Due to the bleeding complications and reported neurotoxic effects, the benefit-to-risk ratio of rt-PA administration rapidly decreases with time and less than $10 \%$ of patients end up receiving treatment [4]. The most significant improvements in interventional management of stroke include the association of rt-PA with endovascular methods [5]. These strategies have enabled to increase the therapeutic window from 3.5 to 6 hours after the first symptoms onset. However, the use of endovascular devices is limited to "easy-to-reach" thrombi and requires highly trained neurointerventionist as well as specific clinical facilities [6]. Thus, there is still a dire need for safe and non-invasive treatments. In addition to the development of other fibrinolytic agents [2, 7], nanomedical approaches for local or targeted delivery of thrombolytic drugs arouse a growing interest [8-10]. Lipid and/or PEGylated nanostructures encapsulating a thrombolytic drug were first reported and showed benefit from increasing the drug half-life [11-14]. More recently, this strategy was combined with active targeting approaches, mostly based on magnetic guidance [15-19]. Once accumulated on the thrombus, nanocarriers improve thrombolytic efficiency while reducing hemorrhagic complications, in preclinical models of thrombosis. The use of an external magnet makes these nanostructures hardly scalable yet in a general clinical setting. Another approach to promote the specific accumulation of the drug relies on functionalizing nanocarriers with antibodies and/or peptides directed against the fibrin network [20-22], against the collagen IV of the vascular basement membrane [23] or against the glycoprotein IIb/IIIa (GPIIb/IIIa) expressed by activated platelets [24-26]. Unlike GPIIb/IIIa, P-selectin has been poorly explored with respect to targeted thrombolysis, although this transmembrane glycoprotein is not expressed by resting platelets in the circulation and is extensively expressed by activated platelets localized 
in the thrombus [27]. In addition, P-selectin is overexpressed by activated endothelial cells, notably in ischemic tissues [28].

In this work, P-selectin was chosen as the molecular target. It has been previously demonstrated in vivo by us and other groups, that fucoidan-functionalized nanoparticles or microparticles targeting P-selectin can be used for the diagnosis of endothelial activation and intraluminal thrombosis, and for tumor-selective drug delivery [29-31]. Fucoidan refers to a type of highly sulfated polysaccharide containing L-fucose groups [32]. This natural compound exhibits a high affinity for P-selectin, mimicking its main ligand the P-selectin Glycoprotein Ligand 1 (PSGL-1) [33]. We report herein the first nanoparticle preparation combining a thrombolytic drug and fucoidan.

Polymer nanoparticles, and especially polysaccharide-based nanoparticles, are promising for the combination of fucoidan with rt-PA [34]. The nanoparticles (NPs) designed in this study were based on polysaccharide-poly(isobutylcyanoacrylate) NPs produced by redox radical emulsion polymerization (RREP). In contrast to the anionic emulsion polymerization, RREP produces stealth NPs with polysaccharides located at the surface in a brush-like structure $[35,36]$. The drug can be loaded by adsorption on the polysaccharide shell to promote its direct availability at the thrombus site and the full retention of its activity. To mimic the free primary amines present in the natural fibrin binding sites, or the L-arginine used to stabilize rt-PA in Actilyse ${ }^{\circledR}$, dextran modified with amino groups was incorporated into the nanoparticle formulation [37]. After demonstrating here that fucoidan can effectively improve in vitro the interaction of fucoidanfunctionalized NPs (Fuco-NPs) with P-selectin under flow, we also evidenced the efficiency of rt-PA-Fuco-NPs in vivo.

\section{Materials and Methods}

\section{Study design}

The aim of this study was to test the therapeutic efficacy of targeted NPs containing a thrombolytic drug, rt-PA in its Actilyse ${ }^{\circledR}$ form. Animal experiments were conducted in C57BL/6 male mice (weight 20-23 g) in respect of the applicable regulation for animal experimentation using protocols approved by the animal care and use committee of the Claude Bernard Institute (APAFIS \#8724, Paris, France). The treatment groups included buffer, vehicle control, free rtPA, non-targeted NPs loaded with rt-PA, and targeted NPs loaded with rt-PA. Unless otherwise 
indicated, 8 to 10 animals per group were investigated and were randomly assigned to the study groups. The experimentalists were blinded to the identity of the study groups while assaying the multiple endpoints in this study.

\section{Products}

Isobutylcyanoacrylate (IBCA) monomers were provided by Orapi (Saint Vulbas, France). Several polysaccharides were used: dextran 40 was purchased from PharmaCosmos (Holbaek, Denmark) and carboxymethyl-dextran 40 (carboxyl content of 5\% w/w) from TdB Consultancy (Uppsala, Sweden). Medium molecular weight fucoidan $(\mathrm{Mn}=18 \mathrm{kDa} / \mathrm{Mw}=104 \mathrm{kDa})$ was a gift from Algues \& Mer (Ouessant, France). NPs were mixed with commercially available rt-PA provided by Boehringer Ingelheim (Ingelheim am Rhein, Germany) in its Actilyse ${ }^{\circledR}$ form. It was reconstituted according to the manufacturer's recommendations and then aliquoted and stored at $-80^{\circ} \mathrm{C}$ for up to 12 months.

\section{Chemical modification of dextran with amino groups}

Amino groups were grafted to dextran chains according to a method described by PrigentRichard et al. [38]. Dextran was dissolved at $0.2 \mathrm{~g} / \mathrm{L}$ in $6.2 \mathrm{M} \mathrm{NaOH}$ and cooled at $4{ }^{\circ} \mathrm{C}$ for 40 minutes and $766 \mathrm{mg}$ of 3-Bromopropylamine hydrobromide (Sigma-Aldrich, Saint-Quentin Fallavier, France) was added, which corresponded to an equivalent of 0.5 molecules per glucose unit. The solution was left to react 4 hours at room temperature under stirring and then neutralized. Modified dextran chains were precipitated in ethanol, solubilized in distilled water and extensively dialyzed against water using a Biotech CE tubing dialysis tubing (MWCO 1,000 Da, Spectrum Europe B.V., Breda, The Netherlands). The polysaccharide was finally freezedried before use. The amine content was determined by isotope-ratio mass spectrometry of nitrogen (IRMS $\mathrm{Nu}$ Horizon, $\mathrm{Nu}$ instruments). The $\mathrm{N}$ content of the aminated dextran was determined to be $0.4 \mathrm{w} / \mathrm{w}$.

\section{Polysaccharide-poly(isobutylcyanoacrylate) nanoparticle synthesis}

$137.5 \mathrm{mg}$ of polysaccharides were dissolved in $8 \mathrm{~mL}$ of a nitric acid solution $(0.2 \mathrm{M})$ and kept 10 minutes at $40^{\circ} \mathrm{C}$ under nitrogen bubbling and magnetic stirring. To synthesize fucoidanfunctionalized NPs (Fuco-NPs), polysaccharides were introduced in the following proportions: 
$10 \% \mathrm{w} / \mathrm{w}$ fucoidan, $40 \% \mathrm{w} / \mathrm{w}$ amino-dextran and 50\% w/w dextran. For Control-NPs, the anionic fucoidan was replaced by anionic carboxymethylated dextran. Ammonium nitrate cerium (IV) ions at $0.08 \mathrm{M}$ in nitric acid $0.2 \mathrm{M}$ were added to the polysaccharide solution, which initiated the formation of radicals. $500 \mu \mathrm{L}$ of IBCA monomers were consequently added, according to the method described by Chauvierre et al. [35]. Nile Red, a hydrophobic fluorescent dye (Sigma Aldrich, Saint Quentin Fallavier, France), dissolved in acetone at $0.5 \mathrm{mg} / \mathrm{mL}$ was incorporated in the medium just after the IBCA to label the hydrophobic core based on the work of Lira et al. [39]. To synthesize similar non-fluorescent NPs, acetone alone was added. The medium was left to react for 50 minutes. $1.25 \mathrm{~mL}$ of a trisodium citrate dihydrate solution at 1.02 $\mathrm{M}$ was added dropwise to inhibit the reaction and the medium was neutralized by $\mathrm{NaOH} 1 \mathrm{M}$. The final suspension was centrifuged at 2,500 $\mathrm{g}$ to remove any large aggregates coming from the block polymerization of IBCA and further dialyzed against water (MWCO $100 \mathrm{kDa})$. In the rest of the study, the term "unloaded NPs" refers to either fluorescent or non-fluorescent Fuco-NPs and Control-NPs that were not loaded with rt-PA.

\section{Physical nanoparticle characterization}

Size and Zeta potential were measured by dynamic light scattering (DLS) and electrophoretic light scattering (ELS) respectively (Zetasizer NanoZS, Malvern Instruments SARL, Orsay, France). Samples were dissolved in distilled water and $\mathrm{KCl} 1 \mathrm{mM}$ for size and zeta potential determination respectively. Particles morphology was visualized by Scanning Electron Microscopy (SEM) (Philips XL 30 ESEM-FEG, Amsterdam, The Netherlands). For all experiments described in this study, NPs were normalized by mass concentration determined after freeze-drying.

Finally, the fucoidan content was determined by a semi-quantitative solid-phase colorimetric assay described by Lee et al. [40]. $4 \mu \mathrm{L}$ of NPs in suspension at a concentration of $20 \mathrm{mg} / \mathrm{mL}$ were dropped off a $1 \times 1 \mathrm{~cm}^{2}$ piece of Whatman Chromatography paper grade 1. This was repeated 6 times on the same point. The paper was left to dry between each drop. The paper was first soaked into a methanol/acetone (6:4) solution for 2 minutes and then into a methanol/acetone/water (6:4:15) solution with $50 \mathrm{mM} \mathrm{HCl}$ and $0.1 \% \mathrm{w} / \mathrm{w}$ methylene blue for 10 minutes. Finally, the paper was extensively washed with acetic acid/methanol/acetone/water $(5: 6: 4: 75)$ until no coloration was seen in the washing solution. The dye adsorbed on the paper 
was extracted with Sodium Dodecyl Sulfate at $2 \% \mathrm{w} / \mathrm{v}$ in methanol for 15 minutes at $50^{\circ} \mathrm{C}$ and its concentration was determined by absorbance reading at $663 \mathrm{~nm}$ on an Infinite ${ }^{\circledR} 200$ PRO microplate reader (TECAN Group Ltd., Männedorf, Switzerland). Standard curves were obtained from fucoidan in solution with known concentrations.

\section{Nanoparticle radiolabeling for biodistribution study}

Fuco-NPs were radiolabeled with ${ }^{99 \mathrm{~m}} \mathrm{Tc}$ to assess their biodistribution. $200 \mathrm{MBq}$ of sodium pertechnetate $\left[{ }^{99 \mathrm{~m}} \mathrm{Tc}\right] \mathrm{Na}$ was mixed with $2.8 \mu \mathrm{g}$ of stannous chloride and $500 \mu \mathrm{g}$ of Fuco-NPs in $\mathrm{NaCl} 0.9 \%$. Stannous chloride is required to reduce pertechnetate and enable an interaction of the reduced radioactive species with the polysaccharide shell of the nanoparticles [41]. The suspension was incubated for 7 minutes at room temperature. Instant thin-layer chromatography (ITLC) was performed to control that the amount of free ${ }^{99 \mathrm{~m}} \mathrm{Tc}$ was $\leq 5 \% .2 \mu \mathrm{L}$ of the suspension were dropped off a silica gel layer (ITLC-SG Varian) and migration was allowed to occur with methyl-ethyl-ketone (minimum $7 \mathrm{~cm}$ ). Thus, no supplementary purification step was performed to eliminate free pertechnetate from radiolabeled Fuco-NPs before injection. In parallel, $1 \mathrm{~mL}$ of the radiolabeled nanoparticles was centrifuged at $6,400 \mathrm{~g}$ for 5 minutes to remove any technetium aggregates. The activities of the supernatant (containing the radiolabeled NPs) and of the pellet (containing large aggregates) were measured with an ionization chamber (Medi 40, Medisystem, Guyancourt, France).

\section{In vivo SPECT/CT imaging}

The animal study was performed in respect of the applicable regulation for animal experimentation and with approval of the animal care and use committee of the Claude Bernard Institute (Autor. APAFIS \#8724, Paris, France).

C57BL/6 male mice (weight 20-23 g) (EJ, Le Genest, St-Berthevin, France) were used for in vivo imaging studies. Mice were kept fully sedated with $1.5-2 \%$ isoflurane during the injection step and the SPECT/CT imaging. $200 \mu \mathrm{L}$ of the radiolabeled suspension (30 MBq) corresponding to $100 \mu \mathrm{g}$ of nanoparticles was injected through the retro-orbital route. SPECT/CT images were acquired 80 minutes after injection, using a nanoSPECT/CT apparatus (Mediso medical imaging systems, Hungary) with 4 detectors. Ultra-high resolution $(0.5 \mathrm{~mm})$ multipinhole whole body mouse collimators were used. In addition, 20 angular projections with 50 
$\mathrm{s} /$ projection and a peak energy window of $140 \mathrm{keV} \pm 20 \%$ were used. Data were reconstructed using the TeraTomo software (Mediso medical imaging systems, Hungary) and a 3D Monte Carlo-based algorithm $\left(64 \times 64\right.$ matrix, voxel size of $0.47 \times 0.47 \times 0.47 \mathrm{~mm}^{3}, 3$ subsets and 48 iterations). Finally, slides were visualized in 3 planes: sagittal, coronal and axial. A 3D movie was also reconstructed.

\section{Tissue biodistribution}

Biodistribution of radiolabeled nanoparticles was performed in 3 mice C57Bl/6 (20-23 g, Janvier, CERJ, Laval, France). Mice were anesthetized with intraperitoneal injection of ketamine (Vétoquinol SA, Lure, France) and xylazine (Bayer SAS, La Garenne-Colombes, France) at 100 $\mathrm{mg} / \mathrm{kg}$ and $10 \mathrm{mg} / \mathrm{kg}$ respectively. Mice were injected through the retro-orbital route, with an activity of $10 \mathrm{MBq}$, corresponding to $100 \mu \mathrm{g}$ of radiolabeled nanoparticles. Mice were sacrificed on average 80 minutes after injection with an overdose of anesthesia. Liver, spleen, kidneys, heart, lungs, brain, testis, a sample of skin (plus hairs), skeletal muscle, bone (femur), blood and urine, were sampled. All samples, as well as the injected solution, were put in pre-weighed plastic vials. The samples were weighed, and their radioactivity was measured in an automated gamma counter (PerkinElmer 1480 WizardT33', Villebon-sur-Yvette, France) collecting 171 and $245 \mathrm{keV}$ gamma rays (window width: 135-300 keV). The results were calculated as percent injected dose per gram of organ (\% ID/g). It is worth highlighting that after 80 minutes, urine had been partially excreted. Therefore the $\% \mathrm{ID} / \mathrm{g}$ value associated to it is an underestimate of what had been eliminated by this way.

\section{Flow binding assay of nanoparticles on recombinant P-selectin}

To evaluate the interaction of unloaded NPs with their molecular target, an in vitro binding assay under flow was developed [42]. Micro-channels of Vena8 Fluoro ${ }^{+}$chambers (Cellix Ltd, Dublin, Ireland) were coated overnight with recombinant human P-selectin (R\&D systems France, Lille, France) at $50 \mu \mathrm{g} / \mathrm{mL}$ and rinsed with $\mathrm{NaCl} 0.9 \%$ just before use.

NPs diluted at $1 \mathrm{mg} / \mathrm{mL}$ in $\mathrm{NaCl} 0.9 \%$ were perfused through channels for 5 minutes either at venous or arterial flow with an ExiGo ${ }^{\mathrm{TM}}$ pump (Cellix Ltd, Dublin, Ireland). Venous and arterial conditions corresponded to a shear stress of $6.75 \mathrm{dyne} / \mathrm{cm}^{2}$ and of $67.5 \mathrm{dyne} / \mathrm{cm}^{2}$, respectively. The binding of NPs was visualized in real time under fluorescence microscopy (Axio Observer, 
Carl Zeiss Microimaging GmbH, Iena, Germany). The quantitative analysis was limited to NP clusters that formed onto the coated channel because of the resolving power of the fluorescence microscope. After rinsing with $\mathrm{NaCl} 0.9 \%, 10$ fields per channel (area of $1230 \mu \mathrm{m} \times 105 \mu \mathrm{m}$ ) were imaged and analyzed with the image analysis software ImageJ (NIH, Bethesda, U.S.) to quantify the number of fluorescent NPs clusters. Unspecific binding was controlled on uncoated channels and on channels coated with Bovine Serum Albumin at $50 \mu \mathrm{g} / \mathrm{mL}$.

\section{rt-PA loading onto nanoparticles}

rt-PA at $0.4 \mathrm{mg} / \mathrm{mL}$ was put in contact with NPs at $0.3 \mathrm{mg} / \mathrm{mL}$ in a total volume of $500 \mu \mathrm{L}$ for 2 hours at $4^{\circ} \mathrm{C}$ under gentle agitation in PBS buffer with $0.01 \% \mathrm{v} / \mathrm{v}$ Tween 20 . The suspensions were then purified by ultrafiltration at 15,000 g with Vivaspin 500 device (Sartorius France SAS, Dourdan, France). A Molecular Weight Cut Off of $300 \mathrm{kDa}$ was chosen to eliminate free rt-PA $(68 \mathrm{kDa})$. Three cycles of washes were performed with the Tween-PBS buffer.

Samples were reconstituted to $500 \mu \mathrm{L}$ with buffer. The protein content of the purified suspensions was determined by Pierce BCA protein assay (Life Technologies SAS, Courtaboeuf, France). A supplementary step to eliminate any artifact coming from the NPs was applied according to the manufacturer's protocol for eliminating interfering substances. $200 \mu \mathrm{L}$ of cold acetone $\left(-20^{\circ} \mathrm{C}\right)$ was added to $50 \mu \mathrm{L}$ of the purified samples and incubated for 30 minutes at $20^{\circ} \mathrm{C}$ to cause protein precipitation. Samples were then centrifuged at $1,000 \mathrm{~g}$ for 10 minutes. The supernatant was poured off and the remaining acetone was allowed to evaporate by leaving the samples 30 minutes at room temperature. $50 \mu \mathrm{L}$ of ultrapure water was added to the protein pellet. $1 \mathrm{~mL}$ of the Pierce BCA protein assay working solution was then added and left 30 minutes at $37^{\circ} \mathrm{C}$. The samples were cooled to room temperature before their absorbance at 562 nm was read on an Infinite ${ }^{\circledR} 200$ PRO microplate reader (TECAN Group Ltd., Männedorf, Switzerland). Standard curves were obtained by diluting Actilyse ${ }^{\circledR}$ in the Tween-PBS buffer and all steps including protein precipitation were followed in parallel.

\section{rt-PA loading efficiency assessed by flow cytometry}

The loading efficiency of rt-PA onto Fuco-NPs was assessed by flow cytometry. Briefly, FITCrt-PA (Abcam) at $0.04 \mathrm{mg} / \mathrm{mL}$ was placed in contact with Nile Red Fuco-NPs at $0.03 \mathrm{mg} / \mathrm{mL}$ for 2 hours at $4^{\circ} \mathrm{C}$ under gentle agitation in PBS buffer with $0.01 \% \mathrm{v} / \mathrm{v}$ Tween 20 . The suspensions 
were added to a PBS solution and were analyzed with a BD FACSAria ${ }^{\mathrm{TM}}$ III flow cytometer (Becton Dickinson). The Nile Red, excited by a $561 \mathrm{~nm}$ laser was detected on a PMT set at $610 / 20 \mathrm{~nm}$ and the FITC rt-PA, excited by a $480 \mathrm{~nm}$, was detected on a PMT set at 530/30 nm. The analysis was performed with the Diva software (Becton Dickinson).

\section{In vitro rt-PA release}

The release of rt-PA from the Fuco-NPs was assessed by flow cytometry. Briefly, FITC-rt-PA (Abcam) at $0.04 \mathrm{mg} / \mathrm{mL}$ was placed in contact with Nile Red Fuco-NPs at $0.03 \mathrm{mg} / \mathrm{mL}$ for 2 hours at $4^{\circ} \mathrm{C}$ under gentle agitation in PBS buffer with $0.01 \% \mathrm{v} / \mathrm{v}$ Tween 20 . The suspensions were added to tubes pre-filled with $300 \mu \mathrm{L}$ of PBS buffer at $37^{\circ} \mathrm{C}$ and placed under gentle agitation at $37^{\circ} \mathrm{C}$ during $0,15,30,45,60$ and 90 minutes. At each time point, they were analyzed at $37^{\circ} \mathrm{C}$ with a BD FACSAria ${ }^{\mathrm{TM}}$ III flow cytometer (Becton Dickinson). The Nile Red, excited by a $561 \mathrm{~nm}$ laser, was detected on a 610/20 nm PMT while the FITC rt-PA, excited at $480 \mathrm{~nm}$, was detected on a 530/30 nm PMT. The analysis was performed with the Diva software (Becton Dickinson).

\section{In vitro amidolytic and fibrinolytic activities of rt-PA-loaded nanoparticles}

Amidolytic and fibrinolytic activities of rt-PA were measured just after loading and compared to free rt-PA normalized at the same concentration based on the Pierce BCA protein assay. Amidolytic activity of rt-PA loaded NPs was assessed with the fluorogenic substrate PefaFluor ${ }^{\circledR}$ tPA (Cryopep, Montpellier, France). Samples were reconstituted after purification. $90 \mu \mathrm{L}$ of purified samples diluted by $1 / 400 \mathrm{v} / \mathrm{v}$ were put in contact with $10 \mu \mathrm{L}$ of PefaFluor ${ }^{\circledR}$ at $5 \mathrm{mM}$. After addition of PefaFluor ${ }^{\circledR}$, a kinetic profile was obtained by measuring the fluorescence level every 30 seconds during 80 minutes at $37^{\circ} \mathrm{C}$ with Infinite ${ }^{\circledR} 200$ PRO microplate reader. Increase of fluorescence corresponded to the formation of a fluorescent product coming from the substrate hydrolysis by rt-PA. Enzymatic velocity was determined from the initial slope of the resulting kinetic profile and compared to that of free rt-PA at the same concentration.

Fibrinolytic activity was assessed with a fibrin lysis assay adapted from the work of Liang et al. [43]. Low melting agarose (Carl Roth GmbH + Co. KG, Karlsruhe, Germany) solution at 3\% $\mathrm{w} / \mathrm{v}$ in TRIS buffer was heated at $65^{\circ} \mathrm{C}$. The solution was cooled at $37^{\circ} \mathrm{C}$ and $2.5 \mathrm{U}$ of thrombin (Sigma-Aldrich) were added. $5 \mathrm{~mL}$ of a fibrinogen (Sigma-Aldrich) solution in TRIS buffer were 
heated at $37^{\circ} \mathrm{C}$ and added. The reaction mixture was poured into $9 \mathrm{~cm}$ culture dish and cooled at $4^{\circ} \mathrm{C}$ for $30 \mathrm{~min}$. On the solidified agar plate, $3 \mathrm{~mm}$ wells were created as sample reservoir. $5 \mu 1$ of reconstituted purified samples diluted by $1 / 15 \mathrm{v} / \mathrm{v}$ were added into the wells and incubated overnight at $37^{\circ} \mathrm{C}$ in a humid atmosphere. After incubation, the lysis area was quantified with ImageJ and compared to that of free rt-PA at the same concentration.

\section{Flow binding assay of nanoparticles on activated platelet aggregates}

To further investigate the binding efficiency of unloaded and loaded NPs to activated platelets, channels of Vena8 Fluoro ${ }^{+}$chambers were coated with $50 \mu \mathrm{g} / \mathrm{mL}$ of fibrillar type I collagen Horm $^{\circledR}$ (Takeda, Linz, Austria) overnight and rinsed with $\mathrm{NaCl} 0.9 \%$ before use. Human whole blood (EFS, Hôpital Bichat, Paris, France) collected on $75 \mu$ M PPACK (Cryopep, Montpellier, France) was perfused at arterial shear rate for 3.5 to 5 minutes to induce platelet activation and aggregation.

In a first set of experiments, the expression of P-selectin by platelet aggregates was controlled by perfusing whole blood containing $20 \mu \mathrm{g} / \mathrm{mL}$ of a FITC-labeled anti-P-selectin antibody or a FITC-labeled matched isotype IgG (Ancell, Bayport, U.S.). After rinsing, 10 fields per channel were imaged and analyzed with the image analysis software ImageJ to compare the fluorescence uptake of aggregates.

In a second set of experiments, PPACK-anticoagulated whole human blood was mixed with 5 $\mu \mathrm{M}$ of $\mathrm{DIOC}_{6}$ (Life Technologies SAS, Saint-Aubin, France), a green fluorescent dye that labels mitochondria of live cells, and perfused at arterial shear stress $\left(67.5 \mathrm{dyne} / \mathrm{cm}^{2}\right)$ to allow platelet aggregation. After rinsing, suspensions of Nile Red-NPs at $1 \mathrm{mg} / \mathrm{mL}$ were then perfused over preformed platelet aggregates at venous shear stress $\left(6.75 \mathrm{dyne} / \mathrm{cm}^{2}\right)$ for 5 minutes. Their accumulation onto activated aggregates was monitored by fluorescence microscopy in real time. After rinsing, 10 fields per channel (area of $1230 \mu \mathrm{m} \times 105 \mu \mathrm{m}$ ) were imaged and analyzed with ImageJ to quantify the level of fluorescent NPs bound to aggregates. Intensity settings were kept the same for both types of NPs. Aggregates were detected using ImageJ by thresholding the green fluorescence level generated by the platelets. The Mean Fluorescence Intensity (MFI) of the NPs on these selected areas was determined using ImageJ. One MFI value was obtained per channel averaged over more than 25 aggregates. 
In a third set of experiments, rt-PA at $0.4 \mathrm{mg} / \mathrm{mL}$ was put in contact with fluorescent NPs at 0.3 $\mathrm{mg} / \mathrm{mL}$ for 2 hours at $4^{\circ} \mathrm{C}$ under gentle agitation in PBS buffer. The suspensions were then purified with three cycles of ultrafiltration at 15,000 $\mathrm{g}$ with Vivaspin 500 device (Sartorius France SAS, Dourdan, France). Finally, loaded NPs were resuspended in PBS just before being perfused at venous shear rate onto activated platelets aggregates marked with $\mathrm{DIOC}_{6}$. Channels were rinsed after 12 minutes of NPs perfusion and 10 fields per channel were imaged and analyzed with ImageJ. One MFI value was obtained per channel by averaging the NPs fluorescence intensity on several aggregates.

\section{In vivo model of thrombosis on mouse mesenteric vein}

$\mathrm{FeCl}_{3}$-induced thrombosis model on mouse mesenteric vein was developed based on the work of Bonnard et al. [44]. C57BL/6 male mice (EJ, Le Genest, St-Berthevin, France) aged from 5 to 8 weeks were chosen for the study. Mice were anesthetized with intraperitoneal injection of ketamine (Vétoquinol SA, Lure, France) and xylazine (Bayer SAS, La Garenne-Colombes, France) at $100 \mathrm{mg} / \mathrm{kg}$ and $10 \mathrm{mg} / \mathrm{kg}$ respectively. A midline abdominal incision was performed to expose the mesentery. The mesentery was gently laid out over a transparent Petri dish lid and vessels were visualized by intravital microscopy (Leica MacroFluo ${ }^{\mathrm{TM}}$, Leica Microsystems SAS, Nanterre Cedex, France) using Orca Flash 4.0 scientific CMOS camera (Hamamatsu Photonics France SARL, Massy, France). Retro-orbital injection of $30 \mu \mathrm{L}$ of Rhodamine 6G (SigmaAldrich) prepared at $0.3 \% \mathrm{w} / \mathrm{v}$ was performed. Rhodamine $6 \mathrm{G}$ fluorescently labeled the platelets and the leukocytes.

A $1 \mathrm{~mm}$ large Whatman chromatography paper soaked into a 10\% w/v iron chloride (SigmaAldrich) solution prepared in saline was then left 1 minute on one of the mesentery veins. After the paper was removed, the vein was washed twice with a saline solution. The veins were measured to have a mean diameter of $171 \pm 31 \mu \mathrm{m}$ (mean $\pm \mathrm{SD}, \mathrm{n}=41$ mice). The thrombus formation was monitored in real-time by fluorescence microscopy by following the accumulation of fluorescently labeled platelets.

\section{Evaluation of in vivo thrombolysis by intravital microscopy}

46 mice were randomly set into 5 groups for the study receiving buffer, Fuco-NPs, reconstituted Actilyse $^{\circledR}$ at $2.5 \mathrm{mg} / \mathrm{kg}$ (rt-PA), Control-NPs associated with Actilyse ${ }^{\circledR}$ normalized to a dose of 
$2.5 \mathrm{mg} / \mathrm{kg}$ (rt-PA-Control-NPs), and Fuco-NPs associated with Actilyse ${ }^{\circledR}$ normalized to a dose of $2.5 \mathrm{mg} / \mathrm{kg}$ (rt-PA-Fuco-NPs).

Samples were prepared on the day of animal experiments. Non-fluorescent Fuco-NPs and Control-NPs at $0.3 \mathrm{mg} / \mathrm{mL}$ in Tween-PBS were mixed with Actilyse ${ }^{\circledR}$ at $0.4 \mathrm{mg} / \mathrm{mL}$ during 2 hours at $4{ }^{\circ} \mathrm{C}$ under gentle agitation as previously detailed. Suspensions were washed 3 times by ultrafiltration using Vivaspin 500 devices (MWCO 300 kDa, Sartorius France SAS, Dourdan, France). After the third ultrafiltration cycle, concentrated samples were used for injection. Amidolytic activity of the concentrated samples was consequently measured with the fluorogenic substrate PefaFluor ${ }^{\circledR}$ tPA and used to normalize the injected dose. Samples were stored on ice and used within 2 hours.

Retro-orbital injection of the different treatments and controls was performed once fluorescently labeled platelets started to aggregate in the injured site and formed a visible thrombus, on average $7 \pm 3$ minutes after thrombosis induction (mean $\pm \mathrm{SD}, \mathrm{n}=41$ mice). This injection method was chosen because it is fast, simple, does not require moving the mouse and ensures a distribution in the circulation similar to that obtained with standard intravenous injection [45]. The injected volumes were of $125 \pm 36 \mu \mathrm{L}$ (mean $\pm \mathrm{SD}$ ), which has been reported to be adapted to the mouse [46]. The thrombus evolution was monitored in real-time by fluorescence imaging (excitation $545 \mathrm{~nm}$ - emission $610 \mathrm{~nm}$ ). Images were acquired just before injection and regularly during the first 15 minutes after injection, then every 5 minutes up to 30 minutes. The thrombus was detected over time using ImageJ by thresholding the fluorescence level. The thrombus density was defined as the total intensity of the detected area. The thrombus relative density was normalized to the peak platelet accumulation for each animal. This parameter was used to assess the benefit of the different treatments compared to the group receiving buffer. It allowed to alleviate the variability between thrombi and was a better estimate of the global thrombolysis trend.

On few additional mice, images were taken continuously over 40 minutes (one image every 10 seconds) to provide typical examples of thrombus formation followed by thrombolysis. In these mice, $\mathrm{DIOC}_{6}$ (Life Technologies SAS, Saint-Aubin, France) was injected at $25 \mu \mathrm{M}$ instead of Rhodamine 6G. These movies were taken for the following groups: rt-PA, rt-PA-Control-NPs, and rt-PA-Fuco-NPs. The nanoparticles used were fluorescently labeled in red with Nile Red and 
1 dual fluorescence imaging was performed (excitation $480 \mathrm{~nm}$ - emission $527 \mathrm{~nm}$ / excitation 545

$2 \mathrm{~nm}-$ emission $610 \mathrm{~nm})$.

3

\section{$4 \quad$ Statistics}

5 Results are presented as mean \pm standard error of the mean $(n \geq 3)$. Statistical significance 6 between experimental groups was assessed using the software GraphPad Prism (GraphPad 7 Software, Inc., La Jolla, U.S.) with 95\% confidence level: ns non-significant, ${ }^{*} \mathrm{p}<0.05$; $8 \quad * * p<0.01 ; * * * p<0.001$. For all tests, data were assumed to be normally distributed. Unpaired 9 non-parametric test (Mann Whitney) was used for samples that contain $\leq 6$ elements. One-way 10 ANOVA with following Post hoc Turkey's test was applied for the in vivo experiments. Grubbs' 11 test was performed on all the data to identify the significant outliers $(\mathrm{p}>0.01)$.

12 

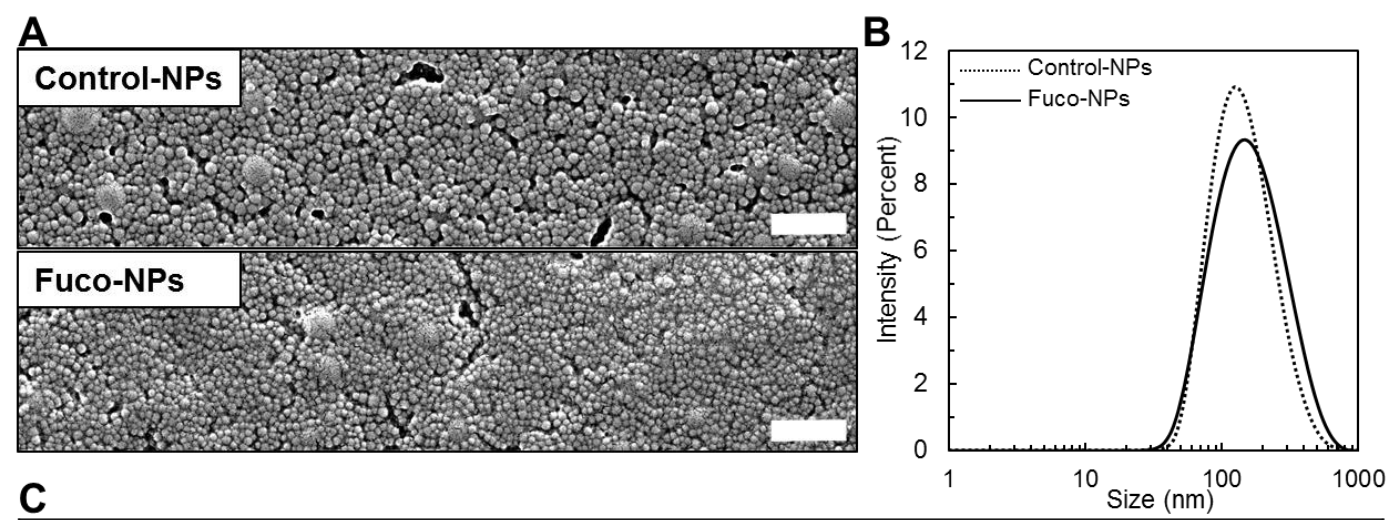

\begin{tabular}{|ccccc|} 
C & & & 1 & 10 \\
Sample & Size $(\mathbf{n m})$ & Pdl & Zeta potential $(\mathbf{m V})$ & Fucoidan content $(\% w / w)$ \\
\hline Control-NPs & $130 \pm 7$ & $0.22 \pm 0.01$ & $-2.5 \pm 0.1$ & - \\
\hline Fuco-NPs & $136 \pm 4$ & $0.24 \pm 0.01$ & $-4.9 \pm 0.4$ & $1.56 \pm 0.20$ \\
\hline
\end{tabular}

Fig 1. Physico-chemical characterization of Control-NPs and Fuco-NPs. A) Scanning Electron Microscopy $(\mathrm{SEM})($ scale bar $=500 \mathrm{~nm})$.

B) Diffusion Light Scattering (DLS) measurement in

NPs made of dextran, aminated dextran and isobutylcyanoacrylate (IBCA) were synthesized by redox radical emulsion polymerization in the presence of either fucoidan (Fuco-NPs) or carboxymethyl-dextran (Control-NPs). Solid spherical NPs were obtained, as shown in SEM images (Figure 1A). The size distribution determined by DLS was similar for both types of NPs, with an average size in intensity of $130 \pm 7 \mathrm{~nm}$ for Control-NPs and $136 \pm 4 \mathrm{~nm}$ for Fuco-NPs (Figures 1B, 1C). Samples exhibited similar polydispersity indexes of $0.22 \pm 0.01$ for Control-

17 NPs and of $0.24 \pm 0.01$ for Fuco-NPs. ELS measurements provided slightly negative zeta 18 potential values of $-2.5 \pm 0.1 \mathrm{mV}$ for Control-NPs and of $-4.9 \pm 0.4 \mathrm{mV}$ for Fuco-NPs (Figure

19 1C) due to the presence of anionic polysaccharides (Fucoidan or carboxymethyl-dextran). The 20 DLS graphs in intensity, number and volume and the ELS graphs corresponding to Figure 1 are 21 reported in supplementary Figure S1. Physical properties of Control-NPs were therefore similar 
1 to those of Fuco-NPs. In addition, Fuco-NPs were composed of $1.56 \pm 0.20 \%$ of fucoidan in mass percent of the total nanoparticle weight (Figure 1C).
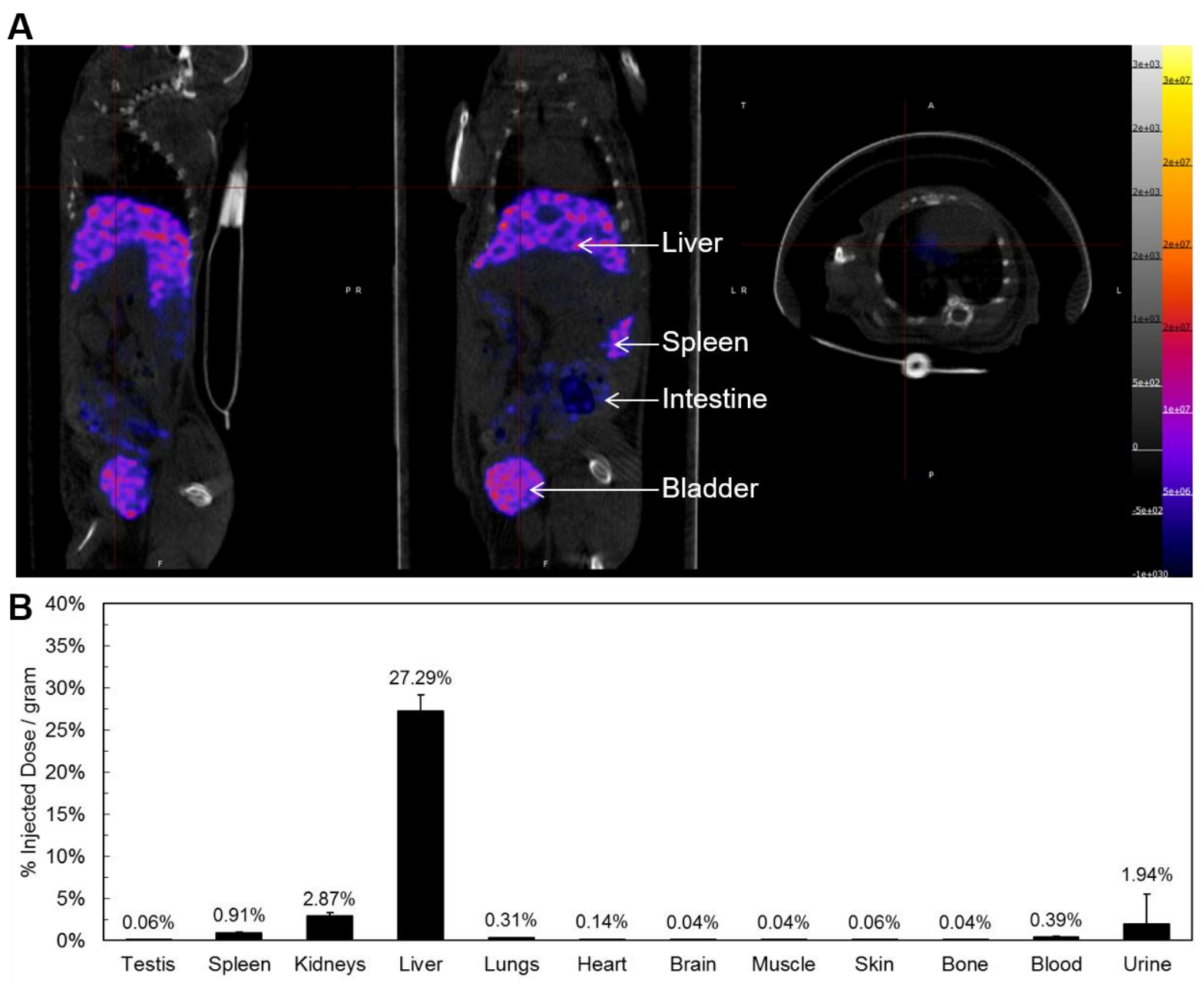

Fig 2. SPECT/CT imaging and tissue biodistribution in mice determined 80 minutes after injection of Fuco-NPs labeled with ${ }^{99 m}$ Tc. A) Representative whole body SPECT/CT imaging: from left to right: sagittal, coronal and axial planes. B) Tissue biodistribution determined by tissue activity 9 measurement normalized to the tissue weight and expressed as a percentage of the injected dose $(n=3$ 10 mice).

11 Fuco-NPs were radiolabeled with ${ }^{99 \mathrm{~m}} \mathrm{Tc}$ and injected in mice for SPECT/CT imaging and tissue 12 biodistribution. SPECT/CT profiles at 80 minutes illustrated in Figure 2 and in supplementary 13 movie S1 showed a classical nanoparticle biodistribution with main accumulation in the bladder 
1 and liver. Some activity was also detected in kidneys and in urine and no signal was detected on

SPECT/CT images in the stomach wall and in the thyroid corroborating a stable nanoparticle labeling. No significant accumulation was noticed in the lungs, the heart and the brain.

\section{Binding of unloaded nanoparticles to P-selectin under flow}
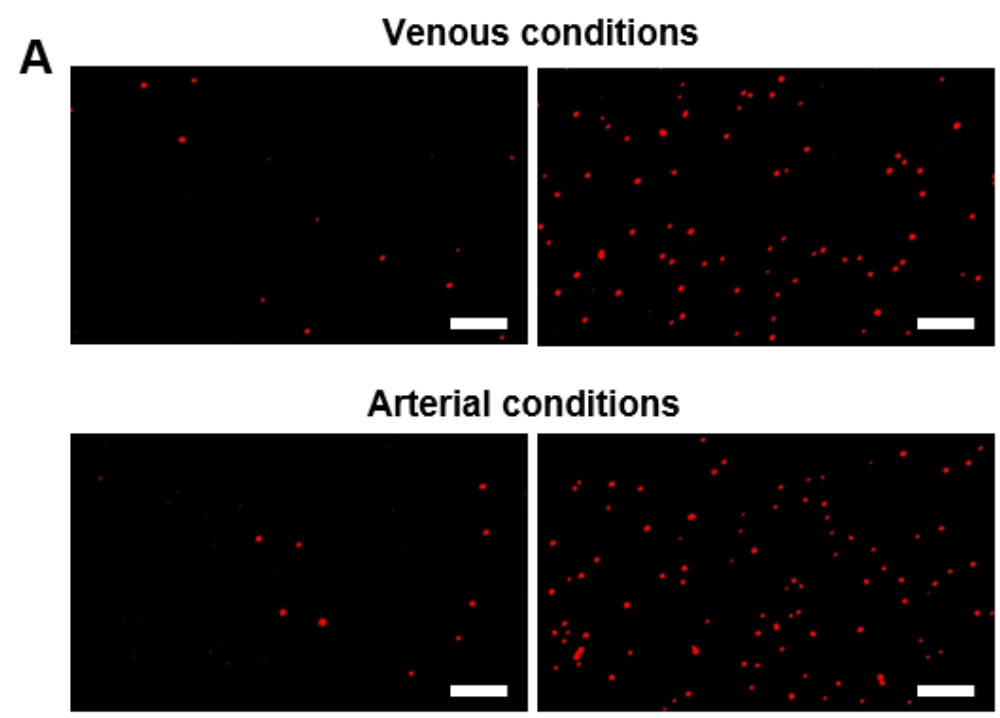

Control-NPs

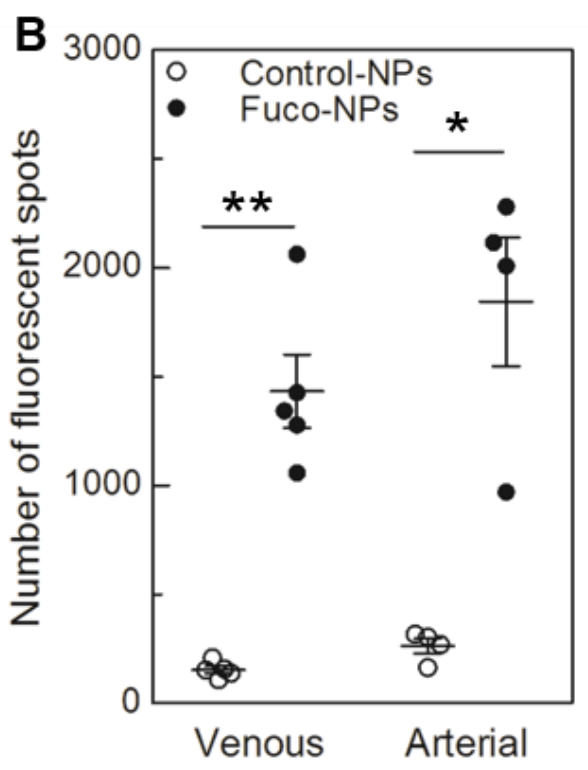

Fig 3. Evaluation of NPs binding on recombinant P-selectin under flow. A) Fluorescently labeled nanoparticles accumulated as clusters on channels coated at $50 \mu \mathrm{g} / \mathrm{mL}$ with P-selectin. Nile Red-labeled Fuco-NPs and Control-NPs were infused in micro-channels at either venous or arterial shear stress for 5 minutes (6.75 and 67.50 dyne $/ \mathrm{cm}^{2}$, respectively) (scale bar $\left.=10 \mu \mathrm{m}\right)$. B) Corresponding quantitative analysis of the number of fluorescent dots on a surface of $1230 \mu \mathrm{m} \times 105 \mu \mathrm{m}\left({ }^{*} \mathrm{p}<0.05 ; * * \mathrm{p}<0.01 ; \mathrm{n}=5\right.$ channels in venous conditions; $\mathrm{n}=4$ channels in arterial conditions).

Unloaded Fuco-NPs were first evaluated to evidence the capacity of fucoidan to interact with its molecular target (Figure 3A). Under venous and arterial conditions, fluorescently labeled FucoNPs accumulated significantly more to P-selectin than Control-NPs, with $1434 \pm 169$ clusters versus $154 \pm 17$ clusters under venous shear stress, and $1844 \pm 297$ clusters versus $264 \pm 34$ clusters under arterial shear stress (Figure 3B). 
A
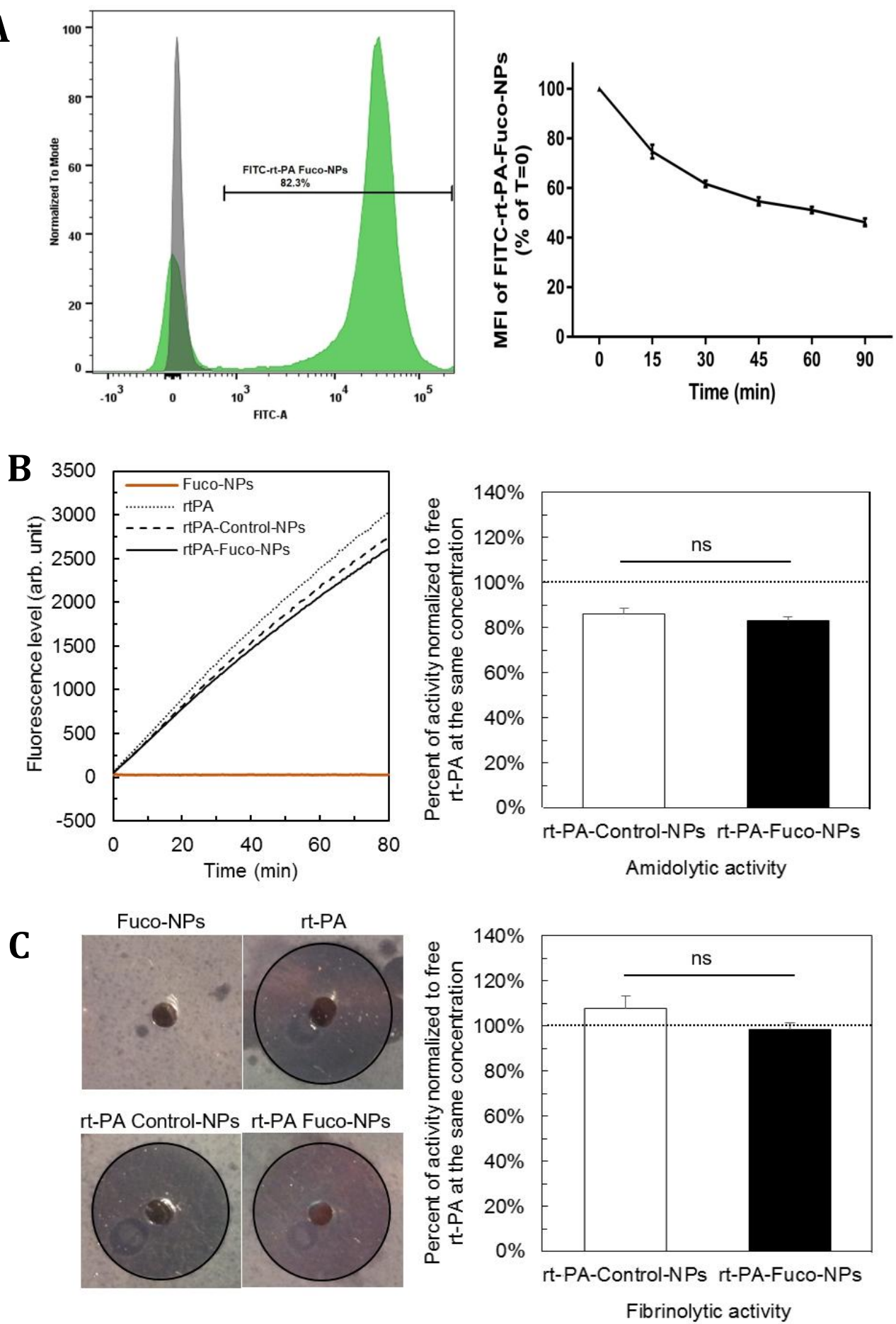

Figure 4. A) Loading efficiency and drug release assessed by flow cytometry. Left: Nile Red Fuco-

4 NPs were loaded either with FITC-rt-PA (green line) or left blank (grey line). More than 80\% of the

5 Fuco-NPs were loaded with FITC-rt-PA. Right: Flow cytometry evaluation of FITC-rt-PA release from

6 Nile Red Fuco-NPs at $37^{\circ} \mathrm{C}$. The MFI (Median Fluorescence Intensity) of FITC-rtPA-Fuco-NPs at 
different time points in PBS buffer. The fluorescence value was normalized over the average value of MFI of FITC-rtPA-Fuco-NPs at time $0 \mathrm{~min} .(\mathrm{n}=3)$. Amidolytic and fibrinolytic activities. B) Amidolytic activities of Fuco-NPs, free rt-PA, rt-PA-Control-NPs and rt-PA-Fuco-NPs measured by the PefaFluor $^{\circledR}$ fluorogenic assay. Left: The tangent gradient is correlated to the enzymatic velocity. Right: Corresponding quantitative analysis normalized to free rt-PA at the same concentration ( $\mathrm{n} \geq 3$

experiments; ns non-significant). C) Fibrinolytic activities of the same samples determined by a fibrinplate agarose assay. Left: The fibrinolytic potential is obtained by measuring the lysed zone area after overnight incubation at $37^{\circ} \mathrm{C}$. Right: Corresponding quantitative analysis normalized to free rt-PA at the same concentration ( $\mathrm{n} \geq 3$ experiments; $n$ s non-significant).

To further evidence the presence of rt-PA on Fuco-NPs, we used FITC-labeled rt-PA and loading efficiency was assessed by flow cytometry analysis. When FITC-rt-PA-loaded Nile Red Fuco-NPs (Figure 4A Left panel, green line) were compared to blank Nile Red Fuco-NPs (grey line), $82.3 \%$ of the fluorescently-conjugated Fuco-NPs were positive. In addition, the restricted coefficient of variation (65.9\%) indicated that the NPs had a uniform coverage of rt-PA.

To further evidence the in vitro release of rt-PA from Fuco-NPs, we used FITC-labeled rt-PA and the drug release was assessed by flow cytometry analysis. As shown in Figure 4A in the right panel, the MFI (Median fluorescence intensity) of the FITC-rtPA loaded onto Fuco-NPs decreased with time. These results showed that rt-PA in PBS buffer at $37^{\circ} \mathrm{C}$ under gentle agitation is gradually released in vitro from Fuco-NPs up to $54 \%$ at 90 minutes.

Quantification of rt-PA adsorbed on the NPs showed that the same amount of drug was retained in rt-PA-Fuco-NPs and in rt-PA-Control-NPs corresponding to $0.35 \pm 0.02 \mathrm{mg}$ of protein per $\mathrm{mg}$ of NPs. Results of the loaded protein enzymatic activity and its activity in contact with fibrin are presented in Figure 4. The amidolytic activity of the rt-PA in contact with Control-NPs and Fuco-NPs decreased by $14 \pm 3 \%$ and $17 \pm 2 \%$ respectively (Figure $4 \mathrm{~B}$ ). The capacity of loaded rt-PA to induce fibrinolysis in the fibrin plate assay was maintained, with values of $108 \pm 6 \%$ for Control-NPs and of $99 \pm 3 \%$ for Fuco-NPs (Figure 4C). Thus, rt-PA loaded onto the NPs kept its full activity in contact with fibrin. No significant difference was observed between both types of NPs enabling to compare them in following experiments. In addition, unloaded Fuco-NPs induced no effect (Figures 4B, 4C). 
A
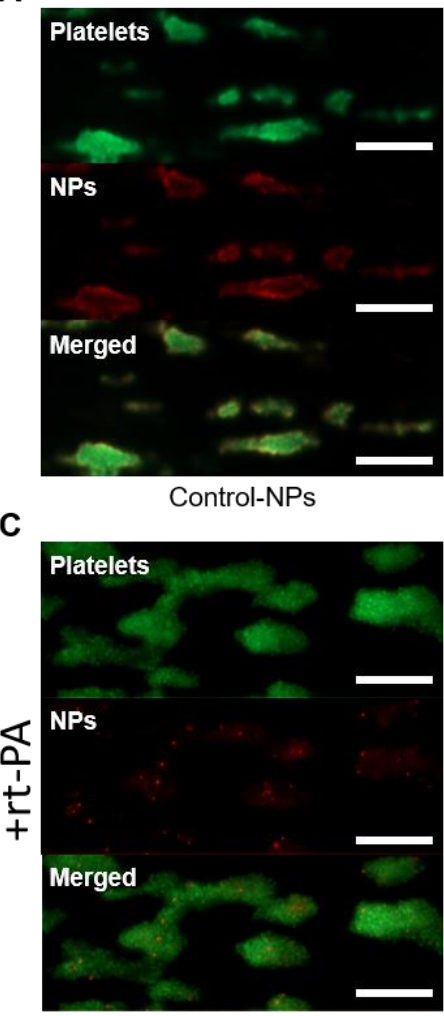

rt-PA-Control-NPs

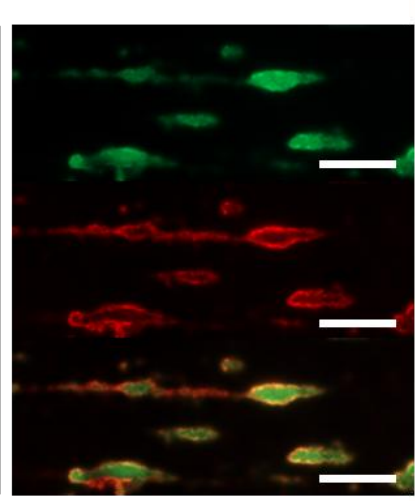

Fuco-NPs

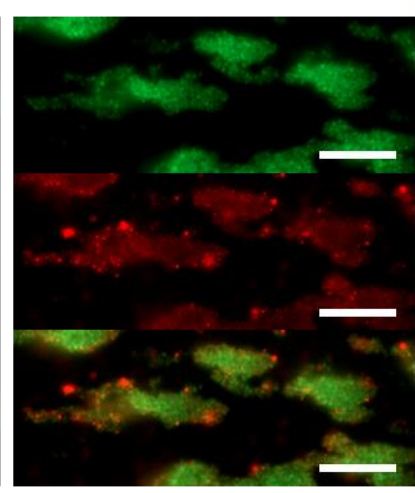

rt-PA-Fuco-NPs

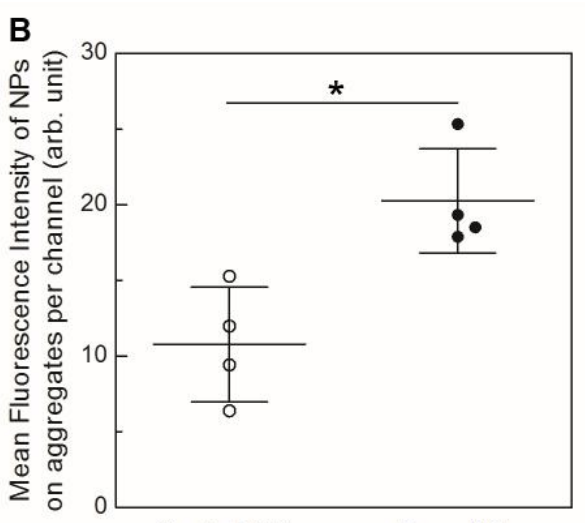

Control-NPs Fuco-NPs

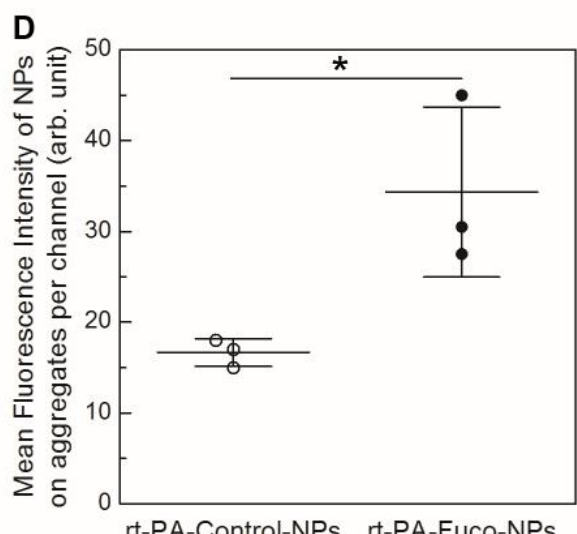

Fig 5. Evaluation of NPs binding on activated platelet aggregates under flow. A) Fluorescence image after infusion for 5 minutes of unloaded Nile Red-nanoparticles (red) onto activated platelets aggregates in venous conditions. Human whole blood mixed with $5 \mu \mathrm{M}$ of $\mathrm{DIOC}_{6}$ (green) was previously infused during 3.5 minutes in collagen coated micro-channels to induce platelet aggregates (scale bar $=50 \mu \mathrm{m}$ ). B) Corresponding quantitative analysis of the Mean Fluorescence Intensity averaged on platelet aggregates. One MFI value was obtained per channel averaged over more than 25 aggregates. Values of 4 independent experiments are reported $(* \mathrm{p}<0.05)$. C) Fluorescence image after infusion for 12 minutes of Nile Red-nanoparticles (red) loaded with rt-PA under similar conditions (scale bar $=50 \mu \mathrm{m}$ ). D)

13 The Fuco-NPs binding efficiency to P-selectin expressed by activated human platelets is

14 illustrated in Figure 5. Perfusion of human whole blood on collagen induced formation of 15 platelet aggregates that expressed P-selectin (supplementary data Figure S2). After perfusion of 16 either Nile Red-Fuco-NPs or Nile Red-Control-NPs on preformed aggregates at venous shear 17 rate, an accumulation of red fluorescence over time was observed at the surface of the platelets. 
1 After perfusion, the fluorescence intensity induced by Fuco-NPs was two-fold higher than that of

2 Control-NPs showing that Fuco-NPs accumulated significantly more onto activated platelets

$3(\mathrm{p}<0.05)$ (Figures 5A, 5B). As shown in Figures 5C and 5D, NPs loaded with rt-PA showed the

4 same trend. After perfusion, a strong fluorescence was observed on the platelet aggregates with

5 rt-PA-Fuco-NPs (Figure 5C). Their accumulation was significantly higher than that of rt-PA-

6 Control-NPs $(\mathrm{p}<0.05)$ (Figure 5D).

7

8 In vivo thrombolytic efficiency

9
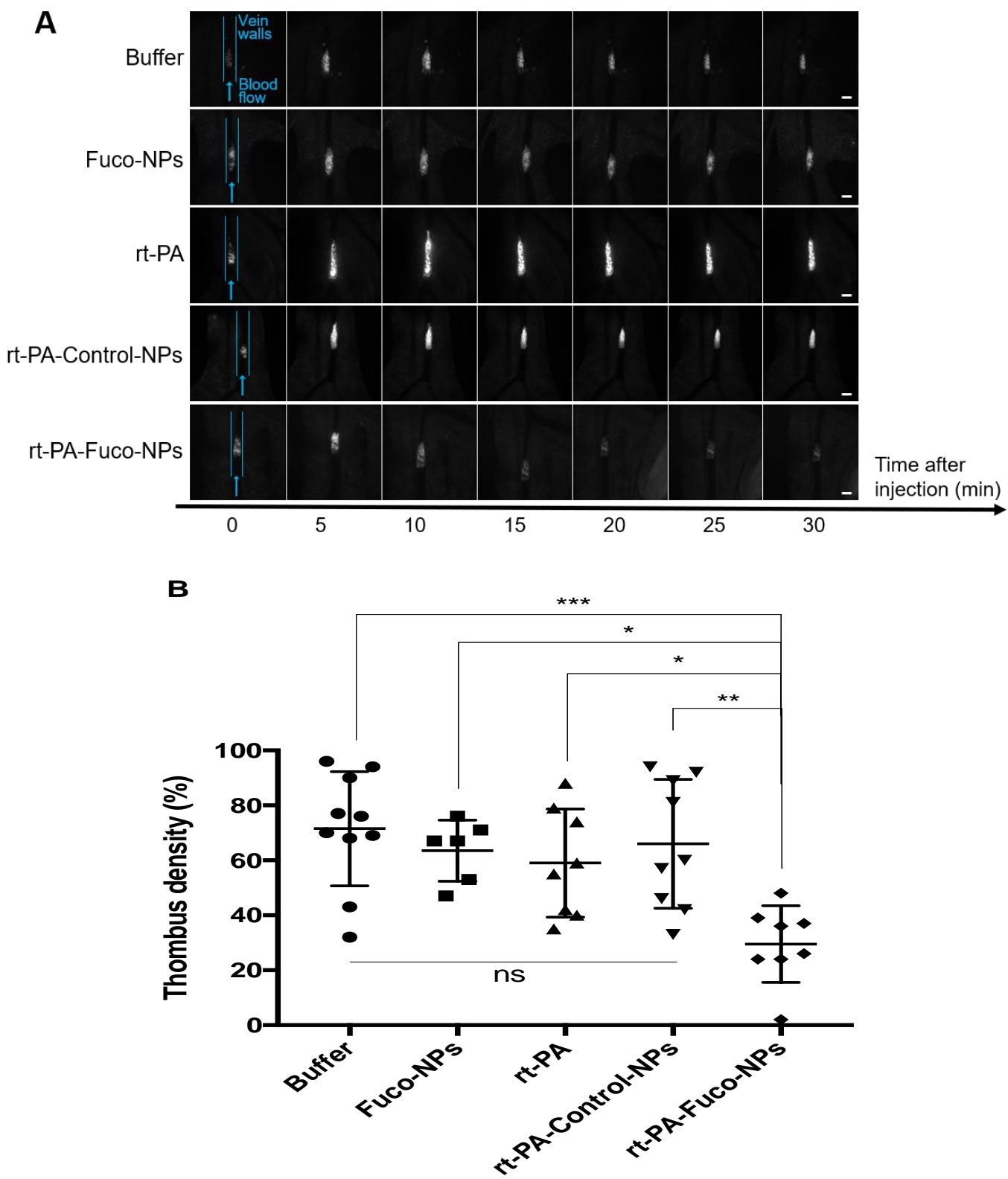
Fig 6. Evaluation of thrombolysis efficiency in a mouse model of venous thrombosis. A) Fluorescence imaging of Rhodamine 6G-labeled platelets at site of thrombosis over time. Representative examples of thrombus evolution as determined by platelet accumulation at different times after injection of buffer, Fuco-NPS, rt-PA, rt-PA-Control-NPs and rt-PA-Fuco-NPs, respectively (scale bar $=200 \mu \mathrm{m}$ ). Prior to injection, circulating platelets were fluorescently labeled with Rhodamine $6 \mathrm{G}$ and thrombosis was generated on a mesenteric vein by applying a $\mathrm{FeCl}_{3}$-soaked paper for 1 minute. B) Thrombus density at 30 minutes after injection. The thrombus density was defined as the fluorescence intensity of the thrombus area normalized to the peak platelet accumulation after injection. Five groups were analyzed $(n=41$ mice). The dose of rt-PA was normalized by the protein amount. The significance is defined with respect to the control group that received buffer (ns: nonstatistically significant; $\left.{ }^{*} \mathrm{p}<0.05 ; * \mathrm{p}<0.01 ; * * * \mathrm{p}<0.001\right)$.

All treatments were administered during thrombus formation. All thrombi experienced a growing phase. In $68 \%$ of mice, the maximum intensity was reached in the first 10 minutes after injection. Figure 6A provides representative examples of thrombus evolution with the different treatments. The thrombus density normalized to the peak intensity for each animal was similar for mice that received buffer as a control $(\mathrm{n}=10)$ and for mice receiving unloaded Fuco-NPs $(\mathrm{n}=6)$, as shown by the quantitative analysis depicted in Figure 6B. In both groups, the thrombus became rapidly stable after reaching a plateau and the relative thrombus density at 30 minutes was around $67.5 \%$ (71.5 $\pm 6.6 \%$ for Buffer and $63.5 \pm 4.5 \%$ for Fuco-NPs $)$. In mice receiving rt-PAbased treatments (rt-PA, rt-PA-Control-NPs and rt-PA-Fuco-NPs), a competition between thrombosis and thrombolysis was observed in the first 15 minutes. However, the overall trend was a fast platelet recruitment followed by a decrease and a stabilization at 30 minutes. Examples of platelet accumulation over time after injection of buffer, Fuco-NPs rt-PA, rt-PAControl-NPs and rt-PA-Fuco-NPs are depicted in Figure 6A. Kinetics can be seen in supplementary data for rt-PA-Fuco-NPs, rt-PA-Control-NPs and rt-PA alone (supplementary movies S2, S3 and S4). rt-PA injection alone at a dose of $2.5 \mathrm{mg} / \mathrm{kg}(\mathrm{n}=8)$ decreased the thrombus density down to $59.0 \pm 7.0 \%$, which was not statistically different from the control group. At this dose, free rt-PA was thus not sufficient to generate a pronounced thrombolytic effect. For rt-PA-Control-NPs injected into 9 mice, the thrombus density was on average $66.0 \pm$ $7.8 \%$ at 30 minutes, which is not statistically different from the rt-PA alone. In contrast, injection of rt-PA-Fuco-NPs $(n=8)$ at a similar dose generated a significant thrombus reduction. The 
density decreased down to $29.5 \pm 4.9 \%$ after 30 minutes. Furthermore, the treatment based on rt-

2 PA-Fuco-NPs was the only one to induce more that $70 \%$ of reduction (density $<30 \%$ ) in 4 mice out of 8 .

\section{Discussion}

In this study, a new strategy for targeted thrombolysis based on polymer NPs functionalized with fucoidan was evaluated (Figure 7). The preclinical study demonstrated the potential of such NPs in acute thrombosis. Fucoidan is an abundant natural polysaccharide that presents no immunogenic risk. It is therefore of great interest in comparison with P-selectin antibodies and recombinant PSGL-1 used to functionalize nano- and microsystems [47, 48]. Fucoidan-based

11 NPs are highly promising nanocarriers to be used in pathologies characterized by overexpression 12 of P-selectin, such as thrombosis. In addition, injection of rt-PA alone to induce thrombolysis has 13 a limited efficiency and is associated to serious side effects. Fucoidan-functionalized NPs were 14 developed as carriers for rt-PA to improve the drug efficiency with the intention to promote its specific accumulation and to decrease the injected dose and side effects.

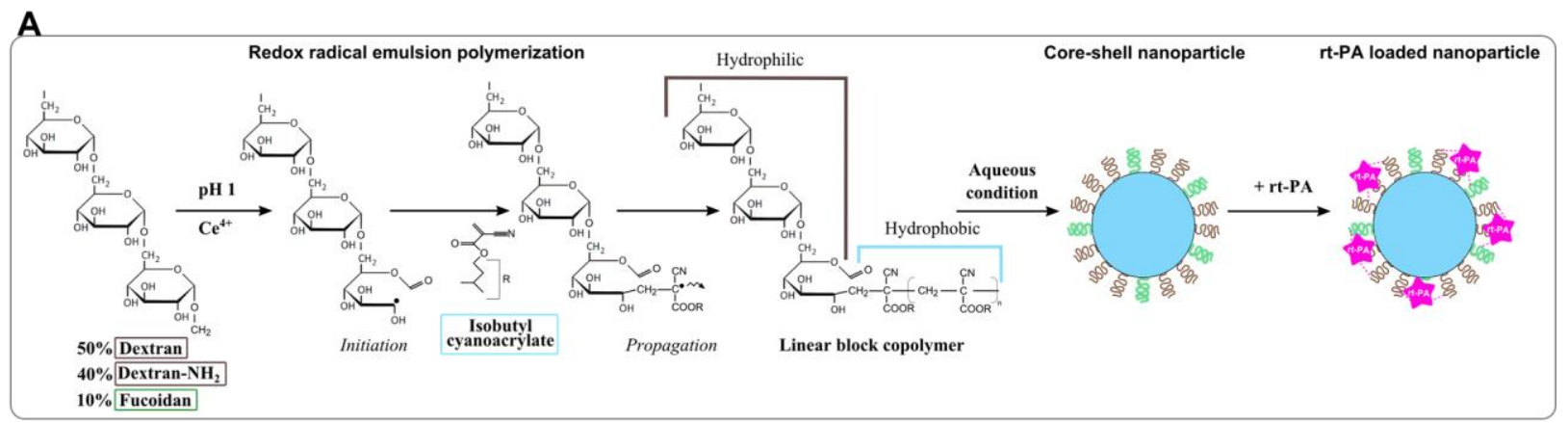

B

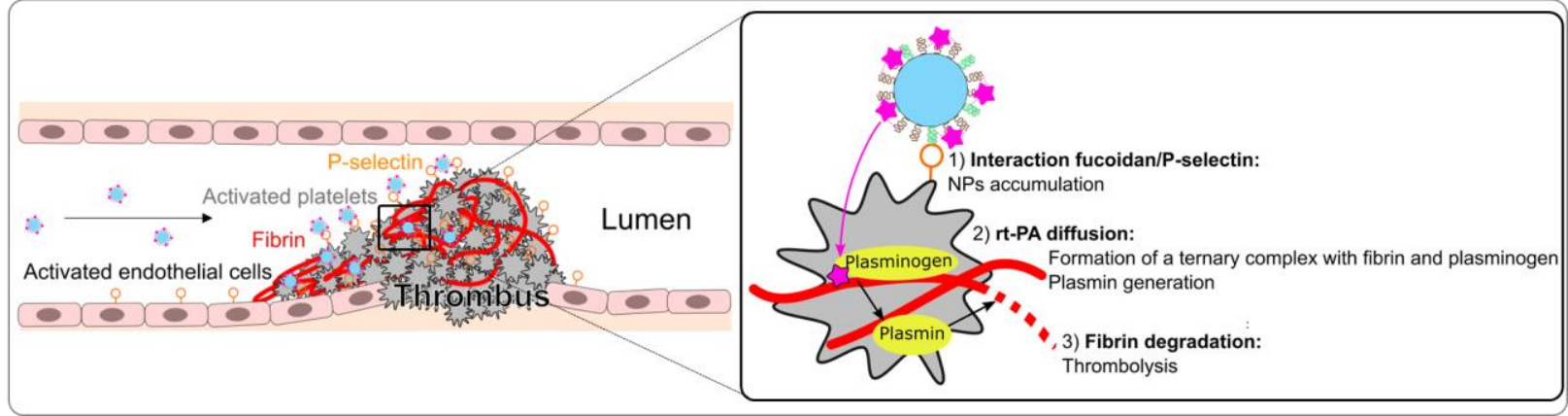

17 Figure 7. A) Nanoparticle formulation. Polysaccharide chains are oxidized by Cerium (IV) ions. The

18 free radical initiates the radical emulsion polymerization of isobutylcyanoacrylate monomers, which 19 creates amphiphilic linear blocks copolymers. In aqueous conditions, they assemble into core-shell 
nanoparticles. rt-PA is mixed with the suspension and interacts with the aminated nanoparticles by electrostatic interactions. B) Nanoparticle interaction with the thrombus. 1) Nanoparticles specifically accumulated on the thrombus via the fucoidan/P-selectin interaction. 2) rt-PA may diffuse within the fibrin network where it forms a ternary complex with plasminogen linked to fibrin. This initiates the formation a plasmin. 3) Plasmin generates fibrinolysis.

Physico-chemical characterizations and biodistribution studies in mice were first performed on unloaded NPs. Spherical NPs with a hydrodynamic diameter of around $130 \mathrm{~nm}$ were obtained (Figure 1). Unspecific NPs (Control-NPs) were synthesized with a negatively charged polysaccharide instead of fucoidan (Figure 1). Carboxymethyl-dextran was chosen as a control to obtain NPs with a slightly negative surface charge but without the sulfate groups of fucoidan that are involved in its interaction with P-selectin [27, 41]. The physical properties of unloaded Control-NPs and Fuco-NPs were similar. The NPs size was in the range of other types of NPs developed for thrombolysis [13-16]. Although the size could be an important parameter, the optimal NP size for interaction with a fibrin network is unknown. The radiolabeled Fuco-NPs biodistribution profile in mice shown by both SPECT images and tissue biodistribution highlighted a partial elimination by the kidneys with a high adsorbed dose in the bladder, followed by a capture of Fuco-NPs by the reticuloendothelial system in the liver. These results are in agreement with a study performed with nanoparticles synthesized by RREP but with a different polysaccharide coating [49]. In our case, no signal was found in the heart, brain or in the lungs. The in vitro binding assays performed on recombinant P-selectin confirmed that fucoidan could efficiently recognize and bind P-selectin, even when incorporated in the polysaccharide shell (Figure 3). Interestingly, this experiment showed that the affinity of FucoNPs for P-selectin was observed both at low shear stress $\left(6.75 \mathrm{dyne} / \mathrm{cm}^{2}\right)$ and at high shear stress (67.5 dyne $\left./ \mathrm{cm}^{2}\right)$, whereas most in vitro affinity assays described in the literature are performed in static conditions $[21,24]$ or at very low $\left(<6.75 \mathrm{dyne} / \mathrm{cm}^{2}\right)$ or uncontrolled shear stress [50, 51]. The analysis of NPs by flow cytometry revealed that $>80 \%$ of NPs were loaded with rt-PA and that the amount of rt-PA per NP was quite homogeneous (Figure 4A). Still, we also found that a minor proportion of NPs was not loaded which indicated that the loading step could be improved. This is a critical issue since non-loaded NPs can potentially compete with loaded ones for P-selectin binding and may have lowered the thrombolytic activity of rt-PA-NP preparations. The in vitro results described in Figure 5 revealed that Fuco-NPs interacted significantly more 
with activated platelet aggregates than Control-NPs. In addition, adsorption of rt-PA did not seem to impair the Fuco-NPs binding efficiency. Thus, these results suggested that the use of rtPA-Fuco-NPs could induce more rt-PA to accumulate into the thrombus.

Fucoidan-functionalized NPs associated with rt-PA were also tested in vitro to evaluate the drug release. At $37^{\circ} \mathrm{C}$ in PBS buffer, the rt-PA could be released continuously from the Fuco-NPs. Then, they were tested in vivo in a mouse model of venous thrombosis induced by iron chloride. This model has the advantage to create a dense and reproducible thrombus within few minutes, in comparison with other standard venous models that require hours or days to develop, and display lack of reproducibility [52]. Buffer alone was injected in 10 mice to evaluate thrombosis standard evolution. In all mice, the maximum platelet accumulation was reached within the first 15 minutes after injection. At 30 minutes the thrombus was therefore considered stable. Figure 6 summarized the preclinical study results. Unloaded Fuco-NPs did not improve significantly the outcome compared with buffer. This result confirmed that unloaded Fuco-NPs have no intrinsic effect on the thrombosis process even if they potentially accumulate on the thrombus. The thrombi in mice receiving free rt-PA or rt-PA-Control-NPs were not significantly different from the ones in the control group. At the used dose, free rt-PA was not sufficient to display a pronounced thrombolytic effect. Moreover, these results indicate that associating rt-PA with a non-targeting nanocarrier had no significant effect on the drug efficiency. In our work, rt-PA is loaded by adsorption post-synthesis, whereas entrapment strategies during the NP synthesis process have mainly been described with non-targeting nanocarriers [12-14]. While covalent binding strategies may avoid premature drug release, it could decrease the protein fibrinolytic activity once on site [53]. In our design, the presence of NPs only slightly affected the drug amidolytic activity and full fibrinolytic activity of the protein was recovered in contact with fibrin (Figures 4B \& 4C). Positively charged aminated dextran was incorporated into the polysaccharide shell to promote electrostatic interaction, mimicking the natural fibrin binding sites. Interestingly, L-arginine is used to stabilize rt-PA pharmaceutical formulations [14, 54]. Alternative functional groups such as lysine could be explored in future studies to load the drug since lysine can bind the kringle domains of rt-PA $[55,56]$.

We found that targeted nanoparticles loaded with rt-PA (rt-PA-Fuco-NPs) significantly improved the outcome at 30 minutes as the thrombus density decreased down to $29.5 \%$. In addition, 4 mice out of 8 showed a decrease $>70 \%$. Despite the risk of desorption from the nanoparticles [57], 
these in vivo results indicated that the loaded protein remained active. Together, these results strongly support the fact that rt-PA and Fuco-NPs had a potent synergistic effect. In addition, the beneficial effect of the targeting strategy was clearly evident after 30 minutes post-induction whereas other targeted nanocarriers described in the literature required more time to improve the drug efficiency $[25,26]$.

The results of this preclinical study suggested that the fucoidan present on the surface of the NPs enhances the thrombolytic efficiency. The in vitro binding assays supported the hypothesis that this is achieved by promoting the accumulation of the NPs on the platelet surface. Injection of $100 \mu \mathrm{g}$ of fluorescent NPs did not allow us to observe any uptake with the limited sensibility of the imaging technique. Once injected at a 20 times higher dose, Fuco-NPs were clearly identified on the edge of the thrombus from the first minute and accumulated for more than 30 minutes (Supplementary Figure S3). This observation is in accordance with other targeting studies with nanoparticles and is promising for future developments of Fuco-NPs [21, 58].

We have used an appropriate but limited number of animals and the mouse model that we have used is far from the complexity and variety of human thrombi. Nevertheless, the present study is a first proof-of-concept for the valuable association of rt-PA with fucoidan-functionalized nanocarriers. The nanocarriers that were used were chosen according to the presence of polysaccharides at the surface and to their stealth properties [59]. The injected concentration was calculated to be about $50 \mu \mathrm{g}$ NPs per $\mathrm{mL}$ of blood. At this concentration, these functionalized nanoparticles exhibit an appropriate cytocompatibility [60,61]. Their biodegradability needs to be considered for future clinical developments. Even if intravital microscopy is a powerful and precise technique in mice to assess thrombosis evolution in terms of platelet recruitment [62], complementary experiments to monitor the blood flow, to evaluate treatment side effects, like bleeding time, and to assess the targeting capacity of rt-PA-Fuco-NPs in vivo in small and large animals, are needed $[24,51]$.

\section{Conclusions}

An efficient thrombolytic agent based on fucoidan-functionalized polymer nanoparticles targeting P-selectin was developed. A flow assay was designed to validate the role of fucoidan at the surface of the nanoparticle. As compared to other strategies that involve grafting antibodies or the use external magnetic force, fucoidan is of great interest for promoting the specific 
accumulation of nanocarriers at site of thrombosis. An in vivo proof-of-concept showed that rtPA loaded fucoidan-nanoparticles improved the thrombolysis efficiency of the drug in thrombosis acute phase. These results highlighted for the first time the relevance of targeting Pselectin for the treatment of thrombosis with rt-PA. Optimization steps of the interactions between the drug and nanoparticles, as well as in-depth studies of the in vivo behavior of loaded nanoparticles should be performed before moving towards clinical implementation.

\section{References and Notes:}

[1] J.R. Marler, T. Brott, J. Broderick, R. Kothari, M. Odonoghue, W. Barsan, T. Tomsick, J. Spilker, R. Miller, L. Sauerbeck, J. Jarrell, J. Kelly, T. Perkins, T. McDonald, M. Rorick, C. Hickey, J. Armitage, C. Perry, K. Thalinger, R. Rhude, J. Schill, P.S. Becker, R.S. Heath, D. Adams, R. Reed, M. Klei, S. Hughes, J. Anthony, D. Baudendistel, C. Zadicoff, M. Rymer, I. Bettinger, P. Laubinger, M. Schmerler, G. Meirose, P. Lyden, K. Rapp, T. Babcock, P. Daum, D. Persona, M. Brody, C. Jackson, S. Lewis, J. Liss, Z. Mahdavi, J. Rothrock, T. Tom, R. Zweifler, J. Dunford, J. Zivin, R. Kobayashi, J. Kunin, J. Licht, R. Rowen, D. Stein, J. Grisolia, F. Martin, E. Chaplin, N. Kaplitz, J. Nelson, A. Neuren, D. Silver, T. Chippendale, E. Diamond, M. Lobatz, D. Murphy, D. Rosenberg, T. Ruel, M. Sadoff, J. Schim, J. Schleimer, R. Atkinson, D. Wentworth, R. Cummings, R. Frink, P. Heublein, J.C. Grotta, T. Degraba, M. Fisher, A. Ramirez, S. Hanson, L. Morgenstern, C. Sills, W. Pasteur, F. Yatsu, K. Andrews, C. Villarcordova, P. Pepe, P. Bratina, L. Greenberg, S. Rozek, K. Simmons, T.G. Kwiatkowski, S.H. Horowitz, R. Libman, R. Kanner, R. Silverman, J. Lamantia, C. Mealie, R. Duarte, R. Donnarumma, M. Okola, V. Cullin, E. Mitchell, S.R. Levine, C.A. Lewandowski, G. Tokarski, N.M. Ramadan, P. Mitsias, M. Gorman, B. Zarowitz, J. Kokkinos, J. Dayno, P. Verro, C. Gymnopoulos, R. Dafer, L. Dolhaberriague, K. Sawaya, S. Daley, M. Mitchell, M. Frankel, B. Mackay, C. Barch, J. Braimah, B. Faherty, J. Macdonald, S. Sailor, A. Cook, H. Karp, B. Nguyen, J. Washington, J. Weissman, M. Williams, T. Williamson, M. Kozinn, L. Hellwick, E.C. Haley, T.P. Bleck, W.S. Cail, G.H. Lindbeck, M.A. Granner, S.S. Wolf, M.W. Gwynn, R.W. Mettetal, C.W.J. Chang, N.J. Solenski, D.G. Brock, G.F. Ford, G.L. Kongable, K.N. Parks, S.S. Wilkinson, M.K. Davis, G.L. Sheppard, D.W. Zontine, K.H. Gustin, N.M. Crowe, S.L. Massey, M. Meyer, K. Gaines, A. Payne, C. Bales, J. Malcolm, R. Barlow, M. Wilson, C. Cape, T. Bertorini, K. Misulis, W. Paulsen, D. Shepard, B.C. Tilley, K.M.A. Welch, S.C. Fagan, M. Lu, S. Patel, E. Masha, J. Verter, J. Boura, J. Main, L. Gordon, N. Maddy, T. Chociemski, J. Windham, H.S. Zadeh, W. Alves, M.F. Keller, J.R. Wenzel, N. Raman, L. Cantwell, A. Warren, K. Smith, E. Bailey, J. Froehlich, J. Breed, J.D. Easton, J.F. Hallenbeck, G. Lan, J.D. Marsh, M.D. Walker, Tissue-plasminogen activator for acute ischemic stroke, N. Engl. J. Med. 333(24) (1995) 1581-1587.

[2] A. Bonaventura, F. Montecucco, F. Dallegri, Update on the effects of treatment with recombinant tissue-type plasminogen activator (rt-PA) in acute ischemic stroke, Expert Opin. Biol. Ther. 16(11) (2016) 1323-1340.

[3] S. Yaghi, A. Eisenberger, J.Z. Willey, Symptomatic Intracerebral Hemorrhage in Acute Ischemic Stroke After Thrombolysis With Intravenous Recombinant Tissue Plasminogen Activator A Review of Natural History and Treatment, JAMA Neurol. 71(9) (2014) 1181-1185.

[4] H. Jaffer, V.B. Morris, D. Stewart, V. Labhasetwar, Advances in stroke therapy, Drug Deliv. Transl. Res. 1(6) (2011) 409-419.

[5] J. Fiehler, C. Cognard, M. Gallitelli, O. Jansen, A. Kobayashi, H.P. Mattle, K.W. Muir, M. Mazighi, K. Schaller, P.D. Schellinger, European Recommendations on Organisation of Interventional Care in Acute Stroke (EROICAS), Int. J. Stroke 11(6) (2016) 701-716.

[6] N. Wahlgren, T. Moreira, P. Michel, T. Steiner, O. Jansen, C. Cognard, H.P. Mattle, W. van Zwam, S. Holmin, T. Tatlisumak, J. Petersson, V. Caso, W. Hacke, M. Mazighi, M. Arnold, U. Fischer, I. Szikora, L. Pierot, J. Fiehler, J. Gralla, F. Fazekas, K.R. Lees, K.S.U. Eso, Eso, Esmint, Esnr, Ean, Mechanical thrombectomy in acute ischemic stroke: Consensus statement by ESO-Karolinska Stroke Update 2014/2015, supported by ESO, ESMINT, ESNR and EAN, Int. J. Stroke 11(1) (2016) 134-147.

[7] B. Piechowski-Jozwiak, J. Bogousslavsky, The use of desmoteplase (bat saliva) in the treatment of ischaemia, Expert Opin. Biol. Ther. 13(3) (2013) 447-453. 
[8] I. Cicha, Thrombosis: Novel nanomedical concepts of diagnosis and treatment, World J. Cardiol. 7(8) (2015) 434-441.

[9] A.K. Silva, D. Letourneur, C. Chauvierre, Polysaccharide nanosystems for future progress in cardiovascular pathologies, Theranostics 4(6) (2014) 579-91.

[10] M. Varna, M. Juenet, R. Bayles, M. Mazighi, C. Chauvierre, D. Letourneur, Nanomedicine as a strategy to fight thrombotic diseases, Future Sci OA 1(4) (2015) FSO46.

[11] P.D. Nguyen, E.A. Orear, A.E. Johnson, E. Patterson, T.L. Whitsett, R. Bhakta, Accelerated thrombolysis and reperfusion in a canine model of myoacardial-infarction by liposomal encapsulation of streptokinase, Circ.Res. 66(3) (1990) 875-878.

[12] J.K. Leach, E. Patterson, E.A. O'Rear, Encapsulation of a plasminogen activator speeds reperfusion, lessens infarct and reduces blood loss in a canine model of coronary artery thrombosis, Thromb. Haemostasis 91(6) (2004) 1213-1218.

[13] J.Y. Kim, J.K. Kim, J.S. Park, Y. Byun, C.K. Kim, The use of PEGylated liposomes to prolong circulation lifetimes of tissue plasminogen activator, Biomaterials 30(29) (2009) 5751-6.

[14] Y. Uesugi, H. Kawata, J.-i. Jo, Y. Saito, Y. Tabata, An ultrasound-responsive nano delivery system of tissuetype plasminogen activator for thrombolytic therapy, J. Control. Release 147(2) (2010) 269-277.

[15] Y.H. Ma, S.Y. Wu, T. Wu, Y.J. Chang, M.Y. Hua, J.P. Chen, Magnetically targeted thrombolysis with recombinant tissue plasminogen activator bound to polyacrylic acid-coated nanoparticles, Biomaterials 30(19) (2009) 3343-51.

[16] F. Bi, J. Zhang, Y. Su, Y.C. Tang, J.N. Liu, Chemical conjugation of urokinase to magnetic nanoparticles for targeted thrombolysis, Biomaterials 30(28) (2009) 5125-30.

[17] H.W. Yang, M.Y. Hua, K.J. Lin, S.P. Wey, R.Y. Tsai, S.Y. Wu, Y.C. Lu, H.L. Liu, T. Wu, Y.H. Ma, Bioconjugation of recombinant tissue plasminogen activator to magnetic nanocarriers for targeted thrombolysis, Int. J. Nanomed. 7 (2012) 5159-73.

[18] J.P. Chen, C.H. Liu, H.L. Hsu, T. Wu, Y.J. Lu, Y.H. Ma, Magnetically controlled release of recombinant tissue plasminogen activator from chitosan nanocomposites for targeted thrombolysis, J. Mat. Chem. B 4(15) (2016) 25782590.

[19] J.N. Hu, W.J. Huang, S.W. Huang, Q.C. Zhuge, K.L. Jin, Y.P. Zhao, Magnetically active Fe3O4 nanorods loaded with tissue plasminogen activator for enhanced thrombolysis, Nano Research 9(9) (2016) 2652-2661.

[20] J.N. Marsh, G. Hu, M.J. Scott, H. Zhang, M.J. Goette, P.J. Gaffney, S.D. Caruthers, S.A. Wickline, D. Abendschein, G.M. Lanza, A fibrin-specific thrombolytic nanomedicine approach to acute ischemic stroke, Nanomedicine 6(4) (2011) 605-615.

[21] J.R. McCarthy, I.Y. Sazonova, S.S. Erdem, T. Hara, B.D. Thompson, P. Patel, I. Botnaru, C.P. Lin, G.L. Reed, R. Weissleder, F.A. Jaffer, Multifunctional nanoagent for thrombus-targeted fibrinolytic therapy, Nanomedicine 7(7) (2012) 1017-1028.

[22] J.Y. Kim, J.H. Ryu, D. Schellingerhout, I.C. Sun, S.K. Lee, S. Jeon, J. Kim, I.C. Kwon, M. Nahrendorf, C.H. Ahn, K. Kim, D.E. Kim, Direct Imaging of Cerebral Thromboemboli Using Computed Tomography and Fibrintargeted Gold Nanoparticles, Theranostics 5(10) (2015) 1098-114.

[23] G. Fredman, N. Kamaly, S. Spolitu, J. Milton, D. Ghorpade, R. Chiasson, G. Kuriakose, M. Perretti, O. Farokzhad, I. Tabas, Targeted nanoparticles containing the proresolving peptide Ac2-26 protect against advanced atherosclerosis in hypercholesterolemic mice, Sci. Transl. Med. 7(275) (2015) $275 \mathrm{ra} 20$.

[24] S. Absar, K. Nahar, Y.M. Kwon, F. Ahsan, Thrombus-targeted nanocarrier attenuates bleeding complications associated with conventional thrombolytic therapy, Pharm. Res. 30(6) (2013) 1663-76.

[25] B. Vaidya, G.P. Agrawal, S.P. Vyas, Platelets directed liposomes for the delivery of streptokinase: development and characterization, Eur. J. Pharm. Sci. 44(5) (2011) 589-94.

[26] J. Zhou, D. Guo, Y. Zhang, W. Wu, H. Ran, Z. Wang, Construction and evaluation of Fe(3)O(4)-based PLGA nanoparticles carrying rtPA used in the detection of thrombosis and in targeted thrombolysis, ACS Appl. Mater. Inter. 6(8) (2014) 5566-76.

[27] K. Ley, The role of selectins in inflammation and disease, Trends Mol. Med. 9(6) (2003) 263-268.

[28] T.R. Porter, Cardiovascular imaging of remote myocardial ischemia: detecting a molecular trace of evidence left behind, Circulation 115(3) (2007) 292-3.

[29] T. Bonnard, G. Yang, A. Petiet, V. Ollivier, O. Haddad, D. Arnaud, L. Louedec, L. Bachelet-Violette, S.M. Derkaoui, D. Letourneur, C. Chauvierre, C. Le Visage, Abdominal aortic aneurysms targeted by functionalized polysaccharide microparticles: a new tool for SPECT imaging, Theranostics 4(6) (2014) 592-603.

[30] M. Suzuki, L. Bachelet-Violette, F. Rouzet, A. Beilvert, G. Autret, M. Maire, C. Menager, L. Louedec, C. Choqueux, P. Saboural, O. Haddad, C. Chauvierre, F. Chaubet, J.B. Michel, J.M. Serfaty, D. Letourneur, Ultrasmall 
superparamagnetic iron oxide nanoparticles coated with fucoidan for molecular MRI of intraluminal thrombus, Nanomedicine 10(1) (2015) 73-87.

[31] Y. Shamay, M. Elkabets, H. Li, J. Shah, S. Brook, F. Wang, K. Adler, E. Baut, M. Scaltriti, P.V. Jena, E.E. Gardner, J.T. Poirier, C.M. Rudin, J. Baselga, A. Haimovitz-Friedman, D.A. Heller, P-selectin is a nanotherapeutic delivery target in the tumor microenvironment, Sci. Transl. Med. 8(345) (2016) $345 \mathrm{ra} 87$.

[32] L. Chollet, P. Saboural, C. Chauvierre, J.N. Villemin, D. Letourneur, F. Chaubet, Fucoidans in Nanomedicine, Mar. Drugs 14(8) (2016).

[33] L. Bachelet, I. Bertholon, D. Lavigne, R. Vassy, M. Jandrot-Perrus, F. Chaubet, D. Letourneur, Affinity of low molecular weight fucoidan for P-selectin triggers its binding to activated human platelets, Biochim. Biophys. Acta 1790(2) (2009) 141-6.

[34] A.K. Silva, M. Juenet, A. Meddahi-Pelle, D. Letourneur, Polysaccharide-based strategies for heart tissue engineering, Carbohydr. Polym. 116 (2015) 267-77.

[35] C. Chauvierre, D. Labarre, P. Couvreur, C. Vauthier, Radical emulsion polymerization of alkylcyanoacrylates initiated by the redox system dextran-cerium(IV) under acidic aqueous conditions, Macromolecules 36(16) (2003) 6018-6027.

[36] I. Bertholon-Rajot, D. Labarre, C. Vauthier, Influence of the initiator system, cerium-polysaccharide, on the surface properties of poly(isobutylcyanoacrylate) nanoparticles, Polymer 46(4) (2005) 1407-1415.

[37] T. Urano, Y. Takada, A. Takada, Stimulation of the amidolytic activity of single chain tissue-type plasminogen activator by fibrinogen degradation products: possible fibrin binding sites on single chain tissue-type plasminogen activator molecule, Biochim. Biophys. Acta 1077(3) (1991) 245-52.

[38] S. Prigent-Richard, M. Cansell, J. Vassy, A. Viron, E. Puvion, J. Jozefonvicz, D. Letourneur, Fluorescent and radiolabeling of polysaccharides: Binding and internalization experiments on vascular cells, J. Biomed. Mater. Res. 40(2) (1998) 275-281.

[39] M.C. Lira, N.S. Santos-Magalhães, V. Nicolas, V. Marsaud, M.P. Silva, G. Ponchel, C. Vauthier, Cytotoxicity and cellular uptake of newly synthesized fucoidan-coated nanoparticles, Eur. J. Pharm. Biopharm. 79(1) (2011) 16270.

[40] J.M. Lee, Z.U. Shin, G.T. Mavlonov, I.Y. Abdurakhmonov, T.H. Yi, Solid-Phase Colorimetric Method for the Quantification of Fucoidan, Appl. Biochem. Biotech. 168(5) (2012) 1019-1024.

[41] P. Saboural, F. Chaubet, F. Rouzet, F. Al-Shoukr, R.B. Azzouna, N. Bouchemal, L. Picton, L. Louedec, M. Maire, L. Rolland, G. Potier, D.L. Guludec, D. Letourneur, C. Chauvierre, Purification of a low molecular weight fucoidan for SPECT molecular imaging of myocardial infarction, Mar. Drugs 12(9) (2014) 4851-67.

[42] B. Li, M. Juenet, R. Aid-Launais, M. Maire, V. Ollivier, D. Letourneur, C. Chauvierre, Development of Polymer Microcapsules Functionalized with Fucoidan to Target P-Selectin Overexpressed in Cardiovascular Diseases, Adv. Healthc. Mater. (2016).

[43] J.F. Liang, H. Song, Y.T. Li, V.C. Yang, A novel heparin/protamine-based pro-drug type delivery system for proteases drugs, J. Pharm. Sci. 89(5) (2000) 664-673.

[44] T. Bonnard, C.E. Hagemeyer, Ferric Chloride-induced Thrombosis Mouse Model on Carotid Artery and Mesentery Vessel, J. Vis. Exp. (100) (2015).

[45] C.D. Steel, A.L. Stephens, S.M. Hahto, S.J. Singletary, R.P. Ciavarra, Comparison of the lateral tail vein and the retro-orbital venous sinus as routes of intravenous drug delivery in a transgenic mouse model, Lab. Anim. (NY) 37(1) (2008) 26-32.

[46] T. Yardeni, M. Eckhaus, H.D. Morris, M. Huizing, S. Hoogstraten-Miller, Retro-orbital injections in mice, Lab. Anim. (NY) 40(5) (2011) 155-60.

[47] M.A. McAteer, J.E. Schneider, Z.A. Ali, N. Warrick, C.A. Bursill, C. von zur Muhlen, D.R. Greaves, S. Neubauer, K.M. Channon, R.P. Choudhury, Magnetic resonance imaging of endothelial adhesion molecules in mouse atherosclerosis using dual-targeted microparticles of iron oxide, Arterioscler. Thromb. Vasc. Biol. 28(1) (2008) 77-83.

[48] B. Mott, W. Packwood, A. Xie, J.T. Belcik, R.P. Taylor, Y. Zhao, B.P. Davidson, J.R. Lindner, Echocardiographic Ischemic Memory Imaging Through Complement-Mediated Vascular Adhesion of Phosphatidylserine-Containing Microbubbles, JACC-Cardiovasc. Imag. 9(8) (2016) 937-46.

[49] K. Alhareth, C. Vauthier, F. Bourasset, C. Gueutin, G. Ponchel, F. Moussa, Conformation of surface-decorating dextran chains affects the pharmacokinetics and biodistribution of doxorubicin-loaded nanoparticles, Eur. J. Pharm. Biopharm. 81(2) (2012) 453-7.

[50] Z. Wu, A. Curaj, S. Fokong, E.A. Liehn, C. Weber, T. Lammers, F. Kiessling, M. Zandvoort van, Rhodamineloaded intercellular adhesion molecule-1-targeted microbubbles for dual-modality imaging under controlled shear stresses, Circ-Cardiovasc. Imag. 6(6) (2013) 974-81. 
[51] X. Wang, Y. Gkanatsas, J. Palasubramaniam, J.D. Hohmann, Y.C. Chen, B. Lim, C.E. Hagemeyer, K. Peter, Thrombus-Targeted Theranostic Microbubbles: A New Technology towards Concurrent Rapid Ultrasound Diagnosis and Bleeding-free Fibrinolytic Treatment of Thrombosis, Theranostics 6(5) (2016) 726-38.

[52] J.A. Diaz, A.T. Obi, D.D. Myers, Jr., S.K. Wrobleski, P.K. Henke, N. Mackman, T.W. Wakefield, Critical review of mouse models of venous thrombosis, Arterioscler. Thromb. Vasc. Biol. 32(3) (2012) 556-62.

[53] R.P. Friedrich, J. Zaloga, E. Schreiber, I.Y. Toth, E. Tombacz, S. Lyer, C. Alexiou, Tissue Plasminogen Activator Binding to Superparamagnetic Iron Oxide Nanoparticle-Covalent Versus Adsorptive Approach, Nanoscale Res. Lett. 11(1) (2016) 297.

[54] H.J. Jin, H. Zhang, M.L. Sun, B.G. Zhang, J.W. Zhang, Urokinase-coated chitosan nanoparticles for thrombolytic therapy: preparation and pharmacodynamics in vivo, J. Thromb.Thrombolys 36(4) (2013) 458-68.

[55] M. Hebert, F. Lesept, D. Vivien, R. Macrez, The story of an exceptional serine protease, tissue-type plasminogen activator (tPA), Rev.Neurol. 172(3) (2016) 186-97.

[56] Z.C. Tang, D. Li, X.J. Wang, H. Gong, Y.F. Luan, Z. Liu, J.L. Brash, H. Chen, A t-PA/nanoparticle conjugate with fully retained enzymatic activity and prolonged circulation time, J. Mat. Chem. B 3(6) (2015) 977-982.

[57] S. Rana, Y.C. Yeh, V.M. Rotello, Engineering the nanoparticle-protein interface: applications and possibilities, Curr. Opin. Chem. Biol. 14(6) (2010) 828-34.

[58] N. Korin, M. Kanapathipillai, B.D. Matthews, M. Crescente, A. Brill, T. Mammoto, K. Ghosh, S. Jurek, S.A. Bencherif, D. Bhatta, A.U. Coskun, C.L. Feldman, D.D. Wagner, D.E. Ingber, Shear-Activated Nanotherapeutics for Drug Targeting to Obstructed Blood Vessels, Science 337(6095) (2012) 738-742.

[59] C. Chauvierre, D. Labarre, P. Couvreur, C. Vauthier, Novel polysaccharide-decorated poly(isobutyl cyanoacrylate) nanoparticles, Pharm. Res. 20(11) (2003) 1786-93.

[60] C. Chauvierre, L. Leclerc, D. Labarre, M. Appel, M.C. Marden, P. Couvreur, C. Vauthier, Enhancing the tolerance of poly(isobutylcyanoacrylate) nanoparticles with a modular surface design, Int. J. Pharm. 338(1-2) (2007) 327-32.

[61] J. Matuszak, J. Baumgartner, J. Zaloga, M. Juenet, A.E. da Silva, D. Franke, G. Almer, I. Texier, D. Faivre, J.M. Metselaar, F.P. Navarro, C. Chauvierre, R. Prassl, L. Dezsi, R. Urbanics, C. Alexiou, H. Mangge, J. Szebeni, D. Letourneur, I. Cicha, Nanoparticles for intravascular applications: physicochemical characterization and cytotoxicity testing, Nanomedicine 11(6) (2016) 597-616.

[62] Y. Boulaftali, L. Lamrani, M.C. Rouzaud, S. Loyau, M. Jandrot-Perrus, M.C. Bouton, B. Ho-Tin-Noe, The mouse dorsal skinfold chamber as a model for the study of thrombolysis by intravital microscopy, Thromb. Haemostasis 107(5) (2012) 962-71.

Acknowledgments:

The authors are most grateful to PLATIN (PLATeau d'Isotopie de Normandie, France) core facility for all elemental analysis used in this study, to Frédéric Nadaud (SAPC, UTC Compiègne, France) for SEM analysis. The authors are thankful to members of the LVTS: Dr M Jandrot-Perrus and S Loyau for advice about rt-PA use, Dr B Ho-Tin-Noe for his expertise in the in vivo model, Dr J C Antunes for advice about protein quantification, and L Louedec for her help with the in vivo procedure. The authors gratefully acknowledge Dr G Almer (Medical University of Graz, Austria) for discussions on fucoidan quantitative analysis.

This study was supported by INSERM, Paris Diderot University, Paris 13 University. This work received the financial support of the ANR-13-LAB1-0005-01 "Fuco-Chem" and the EU project FP7-NMP-2012-LARGE-6-309820 "NanoAthero". Bo Li is grateful to the China Scholarship 
MJ ( $\mathrm{PhD}$ student) performed the synthesis and characterizations of nanoparticles, the rt-PA loading, the in vivo thrombolysis evaluation, participated to all experiments and wrote the draft of the manuscript. RA (Engineer) performed the in vivo model of thrombosis, the in vivo SPECT/CT imaging and the tissue biodistribution. BL (PostDoc) performed the chemical modification of dextran and the in vitro drug release experiments. AB (Trainee in Master) realized the in vitro amidolytic and fibrynolytic tests. JA (Lecturer) carried out the radiolabeling of the nanoparticles. VO (Engineer) performed the flow binding assays. AN (Professor) realized the flow cytometry experiments. DL (Head of the Unit) provided the funding, discussed the results and corrected the manuscript. CC (Researcher) supervised the thesis of MJ, discussed the results and corrected the manuscript.

The authors have declared that no competing interest exists.

\section{Supplementary Materials:}

Figure S1. Physico-chemical characterization of Control-NPs and Fuco-NPs. A) Diffusion Light Scattering (DLS) measurement in intensity, number and volume. B) Electrophoretic Light Scattering (ELS) measurement.

Figure S2. Expression of P-selectin by activated platelet aggregates evidenced by perfusion of FITC-labeled anti-P-selectin. FITC-labeled anti-P-selectin or FITC-labeled IgG with matched isotype were mixed with human whole blood. Blood was perfused in collagen coated microchannels at arterial shear stress $\left(67.5 \mathrm{dyne} / \mathrm{cm}^{2}\right)$. Activation and aggregation of platelets was visualized by phase contrast microscopy and fluorescence microscopy (scale bar $=50 \mu \mathrm{m}$ ).

Figure S3. Accumulation of Fuco-NPs in the thrombus monitored by intravital microscope. $2 \mathrm{mg}$ of Nile Red-labeled Fuco-NPs were injected in mice where thrombosis was previously induced and platelets were labeled in green with $\mathrm{DIOC}_{6}$. Platelet and NP accumulation at site of injury were monitored in real-time up to 40 minutes. Images shown here were taken every 100 seconds.

Movie S1: SPECT/CT imaging at 80 minutes.

Movie S2: Thrombus density over 30 minutes after treatment with rt-PA-Fuco-NPs in a mouse.

Movie S3: Thrombus density over 30 minutes after treatment with rt-PA-Control-NPs in a mouse. 
1 Movie S4: Thrombus density over 30 minutes after treatment with rt-PA in a mouse.

2

3 Graphical abstract: Core-shell polymer nanoparticles are functionalized with fucoidan to target

$4 \quad$ P-selectin and promote the specific accumulation of loaded rt-PA at the thrombus. 